\title{
UN ACADÉMICO FRENTE AL ARTE FEMENINO: JOSÉ FRANCÉS Y EL AÑO ARTÍSTICO (1915-1926)
}

\author{
ISABEL RODRIGO VILLENA \\ Universidad de Castilla-La Mancha
}

\begin{abstract}
Resumen
El crítico de arte y miembro de la Real Academia de Bellas Artes de San Fernando, José Francés, también conocido como Silvio Lago, escribió durante 11 años consecutivos El Año Artístico, un resumen anual de los acontecimientos artísticos españoles acaecidos entre 1915 y 1926, que llegó a ser declarada de utilidad pública en 1924 y traducida a varios idiomas. En esta obra casi enciclopédica, el crítico nombró a 175 mujeres artistas activas en España durante el período señalado, aunque sólo escribió ensayos críticos sobre 14 de ellas. Este artículo pretende dar a conocer el nombre de estas artistas, desvelar los motivos que favorecieron su proyección pública y caracterizar el tono de la crítica de José Francés en el contexto de la polémica de los géneros y de la irrupción de la artista profesional en España.
\end{abstract}

\section{Palabras clave}

José Francés, El Año Artístico, mujeres artistas, crítica de arte, género.

\section{AN ACADEMIC FACING THE WOMEN'S ART: JOSÉ FRANCÉS AND HIS ARTISTIC YEARBOOK (1915-1926)}

\section{Abstract}

The art critic and member of the Royal Academy of Fine Arts of San Fernando, José Frances, also known as "Silvio Lago", wrote for 11 consecutive years The Artistic Year, an annual summary of the Spanish artistic events between 1915 and 1926, which came to be declared of public utility in 1924 and translated into several languages. In this almost encyclopedic work, the critic named 175 female active artists in Spain during the period indicated, but only wrote critical essays about 14 of them. This article aims to give to know the names of these artists, to reveal the reasons that favoured their public projection and to characterize the tone of José Francés' criticism in the context of the controversy of the genres and the irruption of the female professional artist in Spain.

$$
\text { Key words }
$$

José Francés, El Año Artístico, women artists, art criticism, gender. 


\section{José francés y su anuario artístico}

La idea de compendiar en un volumen anuario las actualidades artísticas que iniciara en España Gabriel García Maroto con su resumen de lo acaecido en $1912^{1}$, fue continuada durante algo más de una década por una de las figuras más relevantes de la crítica de arte de la primera mitad del siglo XX: José Francés y Sánchez-Heredero (Madrid, 1883-1963), quien publicó El Año Artístico entre 1915 y $1926^{2}$. Con esta obra casi enciclopédica, traducida al francés, inglés e italiano, el que había sido funcionario de correos y escritor antes que crítico de arte, se ganó su reputación como voz autorizada del arte de su tiempo, que se acrecentó tras su ingreso en la Academia de Bellas Artes de San Fernando, el 4 de febrero de 1923. Entre las muchas competencias que ejerció en la institución, de la que fue secretario perpetuo a partir de $1934^{4}$, su capacidad para intervenir en las decisiones de incorporación de críticos y protectores de las artes o en la concesión de becas a artistas y, muy especialmente, su papel como organizador y jurado de muchas de las Exposiciones Nacionales de Bellas Artes, le otorgaron una notable posición y poder en el sistema del arte español ${ }^{5}$, más visible durante el franquismo. Esta situación favoreció los dos puntos negros que la historiografía atribuye a su impecable currículum: su participación en una "vasta suma de caciquismos", aspecto sobre el que incide Gaña Nuño en su conocido trabajo sobre la crítica de arte en España, y su evolución desde una crítica progresista a otra progresivamente reaccionaria y academista a lo largo de la postguerra. Entre sus grandes logros destacan la difusión del arte de su tiempo, claramente favorecida por el tono poético de sus críticas ${ }^{7}$, el reconocimiento de la caricatura como bella arte, organizando y divulgando los Salones de Humoristas desde 1914, y la publicación del El Año Artístico, auténtico vademécum del arte español entre 1915 y 1926.

\footnotetext{
1 García Maroto, 1913.

${ }^{2}$ La obra completa se puede consultar en la Biblioteca Digital de la Comunidad de Madrid: http://bibliotecavirtualmadrid.org/bvmadrid_publicacion/i18n/consulta/registro.cmd?id=10000001735.

${ }^{3}$ De formación autodidacta, José Francés publicó sus primeros cuentos en Vida Galante (1902). Para tener un sueldo regular que le permitiera escribir, opositó al Cuerpo de Funcionarios de Correos en 1904. Desde 1915 compaginó sus novelas, cuentos y obras teatrales (en 1940 recibió el Premio Nacional de Literatura por su drama Judit) con la crítica de arte. Muchas de sus novelas son a su vez una fuente para el conocimiento del arte español anterior a la Guerra Civil por la frecuente aparición de artistas de la época y el reflejo de la vida cotidiana en los estudios de los pintores. Villalba Salvador, 2001: 368-369.

3 Gaya Nuño, 1975: 307.

4 Véase una descripción detallada de su papel en la Academia en: Villalba Salvador, 2000: 159-191.

5 Villalba Salvador, 1994: V.

${ }^{6}$ Gaya Nuño, 1975: 307.

7 Camón Aznar, 1964: 24-26.
} 


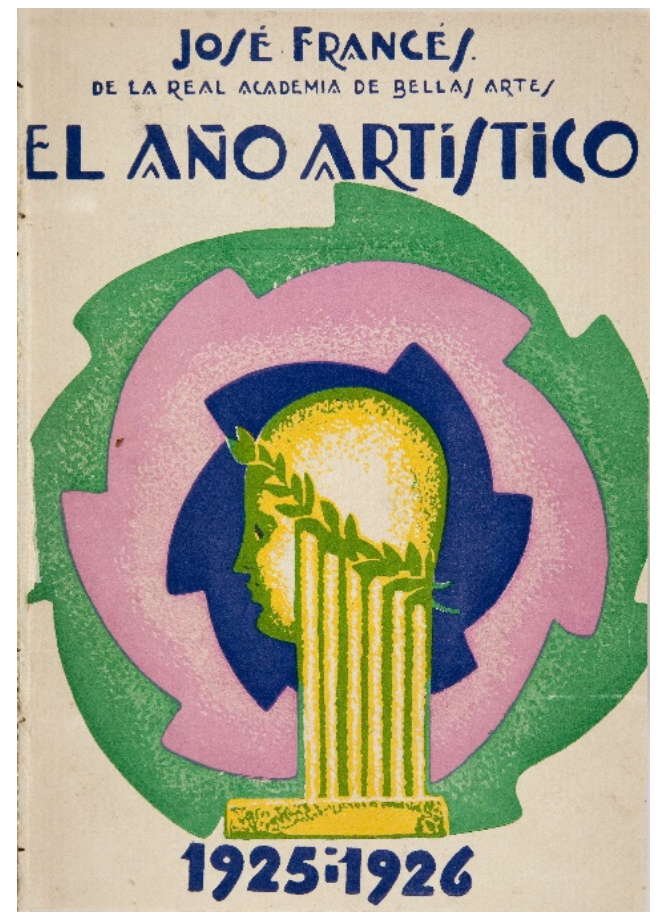

Fig. 1. El Año Artístico. Portada del volumen 1925-1926. Publicado por Editorial Lux, Barcelona, 1928.

La historia de esta publicación está muy relacionada con la del resto de revistas y diarios en las que el crítico colaboró durante esos años, y muy especialmente con La Esfera, de la que refundió el contenido principal. José Francés se inició en la crítica de arte en torno a 1904, escribiendo las crónicas de las Exposiciones Nacionales para la revista Mundo Nuevo. Cuando ingresó en la Academia ya había realizado casi 600 escritos de arte en diarios y revistas madrileñas y catalanas (Alma española, Mercurio, La Actualidad, La Ilustración Españolay Americana, Mundo Gráfico, Vell i Nou, Museum, Cosmópolis, Gaceta de Bellas Artes) y en algunas publicaciones de París, La Habana y Buenos Aires. ${ }^{8}$ También era autor de varios ensayos y monografías de artistas españoles contemporáneos (Anglada, Zuloaga, Pinazo, etc.), sobre los que también disertó en conferencias. Pero fue sobre todo su colaboración durante casi dos décadas en uno de los platos fuertes de la prensa gráfica del momento: La Esfera. Ilustración Mundial (1914-1931), la que consolidaría su trayectoria en la crítica ${ }^{9}$. Dicha publicación, que dirigía Francisco Verdugo dentro del proyecto editorial de Prensa Gráfica, S.A., era una revisa lujosamente editada que presentaba como atractivos principales su novedoso gran tamaño en papel couché $(27,5 \times 36,5 \mathrm{~cm}$.), sus portadas ilustradas a color, sus excelentes fotografías a toda plana, los cuentos y novelas cortas de los escritores más relevantes del momento, incluidos los del propio José Francés ${ }^{10}$, y sus reproducciones artísticas, algunas de las cuales, en separata, la convertían en un publicación de coleccionista.

Muchos de los textos publicados por José Francés en La Esfera se reprodujeron también, con menos estrechez de páginas y menos limitaciones y premura en los tiempos, en el Año Artístico; un proyecto que le reportó éxitos y homenajes, como el recibido en mayo de 1917 en el hotel Ritz, presidido por el Ministro de Instrucción Pública y el Director General de Bellas Artes ${ }^{11}$. El Año Artístico era una publicación periódica con vocación de libro y permanencia, ya que las noticias artísticas recogidas en sus páginas se publicaban un año después de haber tenido lugar, en volúmenes anuales editados por la empresa Mundo Latino de Madrid. Respecto a otros anuarios del mismo tipo, la amplitud de miras y el mayor número

\footnotetext{
${ }^{8}$ Villalba Salvador, 2000: 159.

9 Villalba Salvador, 1994: 49-51.

${ }^{10}$ Una nómina completa de los escritores, críticos de arte, fotógrafos y artistas colaboradores de La Esfera en: Sánchez Vigil, 2003.

${ }^{11}$ Francés, 1918b: 210-215.
} 
de datos recogidos, que incluía, junto a los eventos del estado y de la actualidad madrileña, la actividad artística regional, el arte hispanoamericano y el quehacer de extranjeros en España y españoles en el exterior, lo convirtieron en una de las fuentes principales de noticias artísticas de la época y, en poco tiempo, en una obra de referencia que llegó a ser declarada libro de texto sobre el arte español contemporáneo en varias universidades americanas ${ }^{12} \mathrm{y}$ libro de utilidad pública para las Bibliotecas del Estado en $1924^{13}$.

Seguramente por causas editoriales, que le obligaron a cambiar a la editorial Lux de Barcelona para el volumen que recogía los años 1925 y 1926 (fig. 1), José Francés cesó el proyecto en 1926. No obstante, para estas fechas, su dedicación a la Academia tampoco le permitía el tiempo que requería el seguimiento pormenorizado de las actualidades artísticas, que continuó difundiendo tras la Guerra Civil en una página más limitada de La Vanguardia, llamada también "El Año Artístico"14.

\section{Modernas, sin extridencias: pintoras en el Año Artístico}

Los años en que José Francés se consolida como crítico de arte y escribe su anuario coinciden con los del avance de los derechos, libertades e integración profesional de la mujer tras el acicate de la Guerra Mundial. En el caso particular de las artistas, entre 1915 y 1926 las pintoras, escultoras y artesanas iniciaron un proceso de profesionalización y de integración en el sistema artístico ${ }^{15}$ que parecía dejar atrás la penosa situación de sus colegas del XIX, rechazadas en las academias y obligadas a practicar géneros y técnicas que no tenían consideración social $^{16}$. Prueba de ello fue el aumento de mujeres en la Escuela Superior de Pintura y Escultura y Grabado de Madrid, que pasó de las 6 matriculadas en 1913, a no bajar de las 20-30 por curso en la década siguiente ${ }^{17}$, y la paulatina incorporación femenina a certámenes y exposiciones individuales y colectivas, de cuyo escrupuloso seguimiento, José Francés recupera los nombres de 175 creadoras activas en España en dicho periodo. De todas ellas, citadas en su mayoría dentro de una crónica colectiva, el autor solo dedicó un titular a las pintoras y/o dibujantes: Georgina Agutte, Rosa Bonheur, María del Carmen Corredoira, Sonia Delaunay, Aurora Gutiérrez Larraya, Victoria de Malinowska, Pilar Montaner, Irene Narezo, María Luisa Pérez Herrero, Milada Sindlerová y María Sorolla; y a las escultoras: Eva Aggerholm, Elena Sorolla y Marta Spitzer.

La elección de estos nombres responde a sus propias preferencias artísticas. A José Francés le interesó el arte moderno, pero no la vanguardia, sobre todo una etapa que Villalva Salvador sitúa entre 1915 y 1923, en la que el crítico se interesó por las corrientes catalanas y el neucentismo de Clará, Mir, Casas, Llimona, Beltrán, Humbert, etc., e incluso por los lenguajes más arriesgados de Rafael Barradas, Celso Lagar, Vázquez Díaz, Gregorio Prieto o García Maroto. Su interés por algunos miembros de la Asociación de Artistas Vascos (Gustavo de Maeztu, los hermanos Zubiaurre, Juan de Echevarría, etc.), le llevaron, a su vez, al postimpresionismo francés de Cezanne, Van Gogh y Gaugin. En cambio, desde su nombramiento como académico, y más claramente a partir de 1926, sus críticas se volvieron más conservadoras, adhiriéndose al "retorno al orden" y a la vuelta al clasicismo, en consonancia a lo que reclamaban desde Barcelona Feliu Elías y José María Junoy, y muy en sintonía con crítico francés Camille Mauclair ${ }^{18}$.

\footnotetext{
12 Villalba Salvador, 1994: 94.

13 Melida, 1924: 68-69.

14 Tras la Guerra Civil, José Francés escribió sobre arte en Informaciones, Arriba, Boletín de la Academia de Bellas Artes de San Fernando y en La Vanguardia, de la que fue su crítico de arte entre 1944 y 1960.

${ }^{15}$ Lomba, 2016: 50-69.

16 Sobre las artistas del XIX véase el excelente trabajo: Diego, 1987. También: Muñoz, 2013:103-124.

${ }^{17}$ Datos extraídos de la Escuela Especial de Pintura, Escultura y Grabado de Madrid, que se encuentran en el Archivo General Universidad Complutense (A.G.U.C.M.).

18 Villalba Salvador, 1994: IX-X.
} 


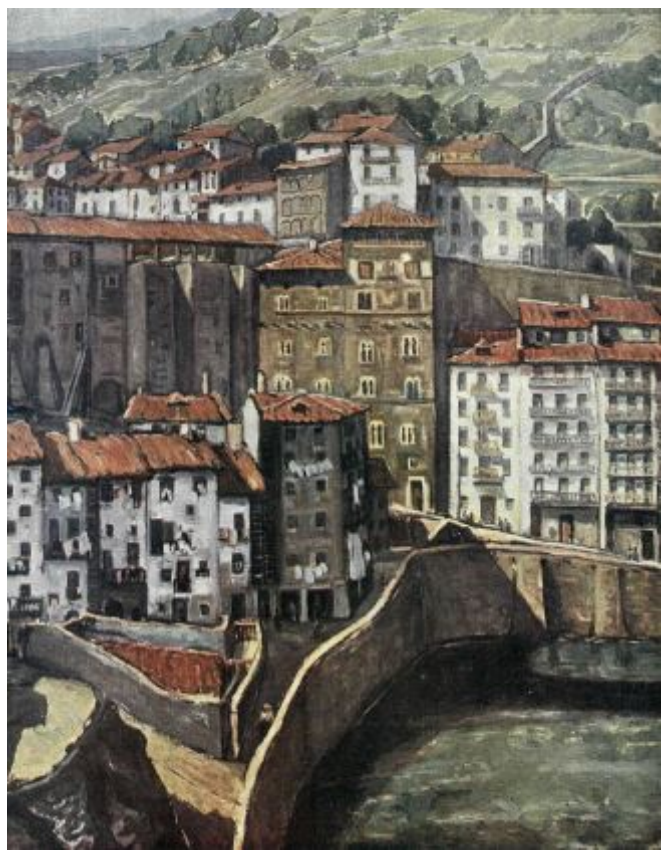

Fig. 2. Victoria de Malinowska. Pequeñas pescadoras de Ondarroa. 1918. Óleo/tela, 94,5 x $75 \mathrm{~cm}$. Museo San Telmo. San Sebastián.

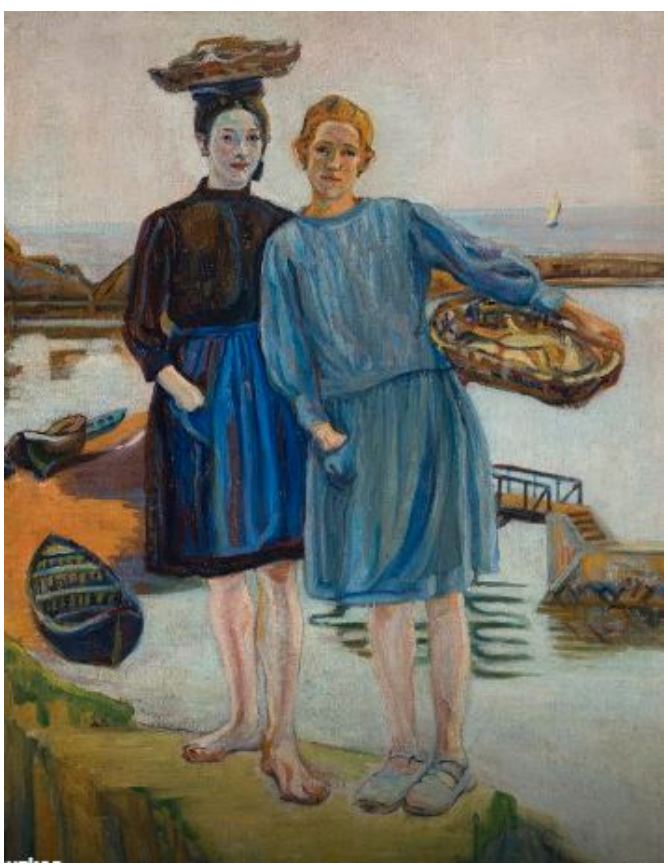

Fig. 3. Milada Sindlerová. Puerto del norte (España). Publicada en La Esfera $(15-12-1917)$

Todo esto se verá reflejado en las artistas que admiró y en las que recriminó u omitió en El Año Artístico. Su rechazo a la experimentación vanguardista se aprecia en sus juicios sobre la pintora María Gutiérrez Cueto, más conocida como María Blanchard (1881-1932), que participó en la "Exposición de Pintores Íntegros" organizada por Ramón Gómez de la Serna en 1915, antes de su marcha definitiva a París. Sin una significación programática ni una clara planificación de mercado; lanzada, según Brihuega, a modo de coqueteo futurista ${ }^{19}$, la de los "Íntegros" fue la primera aproximación al cubismo en Madrid y la primera exposición del recién inaugurado Salón de Arte Moderno. En ella exponían en extraña amalgama: Diego Rivera, María Gutiérrez Cueto, Luis Bagaria y el escultor Agustín "El Choco". José Francés se mostró irónico ante el experimento de Gómez de la Serna, de cuyas palabras en el prólogo del catálogo decía que estaban "llenas de belleza" y de "equilibrios habilidosísimos de concepto para defender lo indefendible" 20 , y exceptuando las caricaturas expuestas, rechazó rotundamente el cambio de orientación estilística de Ribera y Blanchard, pidiéndoles que retomaran a sus bellos y armónicos cuadros de antes, ejemplo de los cuales citaba Los primeros pasos y Ninfas encadenando a Sileno, por los cuales Blanchard había obtenido una tercera y segunda medalla en las Exposiciones Nacionales de 1908 y 1910. En favor del crítico debe decirse que no emitió juicios sobre la deformidad física de la autora, habituales, sin embargo, en la bibliografía de Blanchard ${ }^{21}$.

Lo que menos gustaba a José Francés del arte novísimo era la intelectualización, esa tendencia a olvidar la pintura detrás de "palabras, palabras y palabras" ${ }^{22}$, según explicó a propósito de otro de los hitos divulgativos de la vanguardia en España: la Exposición de Pintores Polacos en los patios del Ministerio de Estado (abril 1918), en la que participaban el matrimonio formado por Wanda y Josez Panckiewicz, junto a Wladyslaw Jahl y Waclaw Zawadowski, con obras que le resultaban tan "abstrusas y herméticas" como las boutades

\footnotetext{
${ }^{19}$ Brihuega, 1981:183-184.

${ }^{20}$ Francés, 1916a: 52-53.

21 Muñoz, 2009: 84.

22 Francés, 1919b: 119-122.
} 
literarias con que pretendían explicarlas. Así que no veía en la exposición un trabajo serio, porque ni siquiera las obras eran fieles a los contenidos que intentaban expresarlas, y sólo salvó de la hoguera a una mujer: Wanda Pankiewicz (1864-1946), pero no por sus pinturas, "inferiores a las del Sr. Pankiewicz" -según decía-, sino por sus trabajos decorativos, especialidad por la que el crítico mostró un notable interés en la revista:

"En cambio, sus tapicerías son realmente bellas, de un buen busto y de una riqueza decorativa indudable. Estas obras de la Sra. Pankiewicz son muy interesantes. Ahora que por fin parece que en España empiezan a darse cuenta los pintores y los críticos de la importancia de las artes aplicadas, las tapicerías de la Sra. Pankiewicz me parecen un hermoso ejemplo"23.

Más que un absoluto rechazo, la postura de José Francés frente a los ismos fue la de extraer de los pintores renovadores la parte sustancial que estaba por encima de las extravagancias, lo cual le permitió defender a figuras como Daniel Vázquez Díaz, que era para él "uno de los grandes pintores modernos que hoy necesita España para despertarse y lavarse de negruras roñosas" 24 ; a Celso Lagar, en quien encontraba una gran sensibilidad y un sentido muy justo del color detrás de su arrogancia fauvista, y del que llegó a afirmar que era un "académico de las Bellas Extravagancias" 25; o a Rafael Barradas, pintor sensible y no un arribista plagiario, que actuaba movido por sus deseos sinceros de novedad y por sus propias inquietudes visuales y sensoriales, tras las cuales había un dibujo y una composición perfectos ${ }^{26}$.

Esta postura de tentativa entre la aceptación o no de los movimientos de vanguardia; del valor de lo original pero no de la mera intelectualización literaria, explica su interés por otra vanguardista: Sonia Delaunay (1885-1979), de quien también aceptó su aplicación plástica al ámbito decorativo, desinteresándose de sus pinturas.

El matrimonio Robert y Sonia Delaunay había llegado a Madrid a finales de 1914. Durante los escasos meses que vivieron en la capital antes de instalarse en Portugal, la artista se inscribió como copista en el Museo de Prado, incorporando a sus cuadros abstractos de entonces figuras que dejaban ver la influencia de los maestros clásicos y su interés por el baile flamenco ${ }^{27}$. José Francés se interesó por Sonia Delaunay durante su segundo período en Madrid, entre 1917 y 1929, una época en que la artista, tras haber perdido su renta familiar procedente de Rusia, decidió poner en práctica ideas que ya estaban en su mente en el período portugués, fundando la firma "Casa Sonia", dedicada a la decoración de interiores y al diseño de moda. Las revistas de la época difundieron en imágenes la aplicación de sus teorías simultaneístas a proyectos decorativos como el del Petit Casino de Madrid, y a varias residencias de la burguesía y la nobleza local que emulaban en gusto por lo parisino ${ }^{28}$. En el texto que escribió José Francés sobre su exposición de objetos decorativos en la librería Mateu, el crítico aplaudía la contribución de su propuesta moderna a la renovación del ambiente artístico madrileño con las siguientes palabras:

"Sonia Delaunay ha transformado el Salón Mateu en una extraña fantasmagoría de luces, de colores y de formas rítmicas [...]

La artista rusa, esposada de un admirable pintor francés, Roberto Delaunay, aparece en Madrid durante el período tumultuario de la guerra. Su paso empieza a notarse en las casas aristocráticas, en algunas tiendas aletargadas antes bajo los prejuicios de rancios estilos. [...] $\mathrm{Da}$, incluso, a teatros y cabarets su oportuna frivolidad $[\ldots]$

De este modo la Exposición Sonia es como una fiesta para los sentidos, como una feria de espiritualidades que llega oportuna en este Madrid renovado afortunadamente [...]"29.

\footnotetext{
${ }^{23}$ Francés, 1919b: 121-122.

${ }^{24}$ Francés, 1922: 77.

${ }^{25}$ Francés, 1919f: 353-355.

26 Vid.: Francés, 1920a: 118-119 y Francés, 1923b: 248.

27 Ruiz del Árbol, 2017: 59-69.

${ }_{28}^{8}$ Ruiz del Árbol, 2017: 87-107.

${ }^{29}$ Francés, 1921f: 392-394.
} 
Con todo, su rechazo a las vanguardias más intelectualizadas le llevaría a centrar su atención en mujeres artistas situadas en la línea de la renovación francesa impresionista y de un postimpresionismo amplio que llegaba hasta el fauvismo, que era donde se movían sus preferencias; un interés por la estética francesa que se verá acrecentada a partir de la Exposición de Arte Francés de Barcelona en 1917. Por tanto, las pintoras sobre las que más tinta desplegó, españolas o extranjeras, fueron impresionistas, postimpresionistas o artífices de un realismo más o menos expresivo, caso de la ruso-polaca Victoria de Malinowska, la checa Milada Sindlerová, la francesa Georgine Agutte, la mexicana Irene Narezo y las españolas: María Luisa Pérez Herrero, Pilar Montaner, María Sorolla y María del Carmen Corredoira.

Empezando por las extranjeras, de la joven pintora rusa de origen polaco, Victoria de Malinowska (1890-¿?), otra de las artistas que, como Sonia Delaunay y Wanda Pankiewicz, llegaron a España desde París huyendo del conflicto mundial ${ }^{30}$, José Francés trazó su recorrido español refiriendo su presencia en más de diez exposiciones celebradas entre 1918 y 1926 en Madrid, Barcelona, Bilbao y San Sebastián, lugar este último donde estuvo vinculada a la Asociación de Artistas Vascos y a los hermanos Zubiaurre ${ }^{31}$. A lo largo de esta trayectoria, Malinowska recibió críticas positivas y otras menos halagadoras. Entre las últimas, cuando expuso en el Círculo de Bellas Artes de Madrid en junio de 1918, se le achacó un abuso de lo naif que hacía que sus obras parecieran de principiante ${ }^{32}$. A José Francés, por el contrario, le agradaron su ingenuidad y su sencillez juvenil, tras las cuales encontraba grandes dotes en el dibujo y la composición, y un armonioso y apasionado colorido, sobre todo en sus paisajes, género donde la artista se mostraba más libre y personal ${ }^{33}$. Más extensamente, en el artículo que escribió tras exponer en los patios del Ministerio de Estado (1920) más de doscientas obras entre retratos, paisajes y bodegones, José Francés encontraba en la autora resabios del impresionismo francés, como ella misma había reconocido en una entrevista concedida a la revista Voluntad, donde decía ser heredera de Renoir, Monet y Sisley, y sentirse "muy moderna, sin llegar [...] al ultramodernismo" ${ }^{34}$. En opinión de José Francés:

"Ante todo resaltaba en la Exposición de Victoria de Malinowska su optimismo cromático, el amor a las gamas claras, el feliz instinto decorativo. Y el buen gusto [...]. Así sus cuadros causan alegre sensación de brillantez y diafanidad, brotada tanto de los temas pictóricos como de esa aguda sensibilidad, con que la señorita Malinowska comprende e interpreta el color.

$\mathrm{Y}$ a veces, cuando es preciso, da también el resultado de una pintura enérgica firmemente constructivista, como en los retratos del músico Bretón, por ejemplo.

Retratos femeninos (fig. 2) e infantiles tenía muchos deliciosos, y sus notas de flores, sus paisajes del Norte y de la sierra madrileña causaban en el espectador ese deleite intelectual y sensitivo que es una de las características de la pintura moderna"35.

Inquietudes parecidas encontró José Francés en la obra de otra de las artistas que formaban la colonia de refugiados en España durante la Guerra Mundial: la pintora checa Milada Sindlerová (1875-1941), afincada temporalmente en el País Vasco, donde asistía a

\footnotetext{
${ }^{30}$ Cabañas Bravo, 2001: 231.

31 También es conocida su amistad con Zuloaga, quien la inmortalizó en París en el retrato conocido como La Rusa (1912), propiedad del MNCARS. No registro AS00412.

32 Opiniones de Rafael Doménech en $A B C$ (27-6-1917) y de Juan de la Encina en España (27-6-1917) recogidas en: García, 2002: 146.

${ }^{33}$ Francés, 1919g: 356.

34 Anónimo, 1 de febrero de 1920: 9.

${ }^{35}$ Francés, 1921b: 158-159.
} 


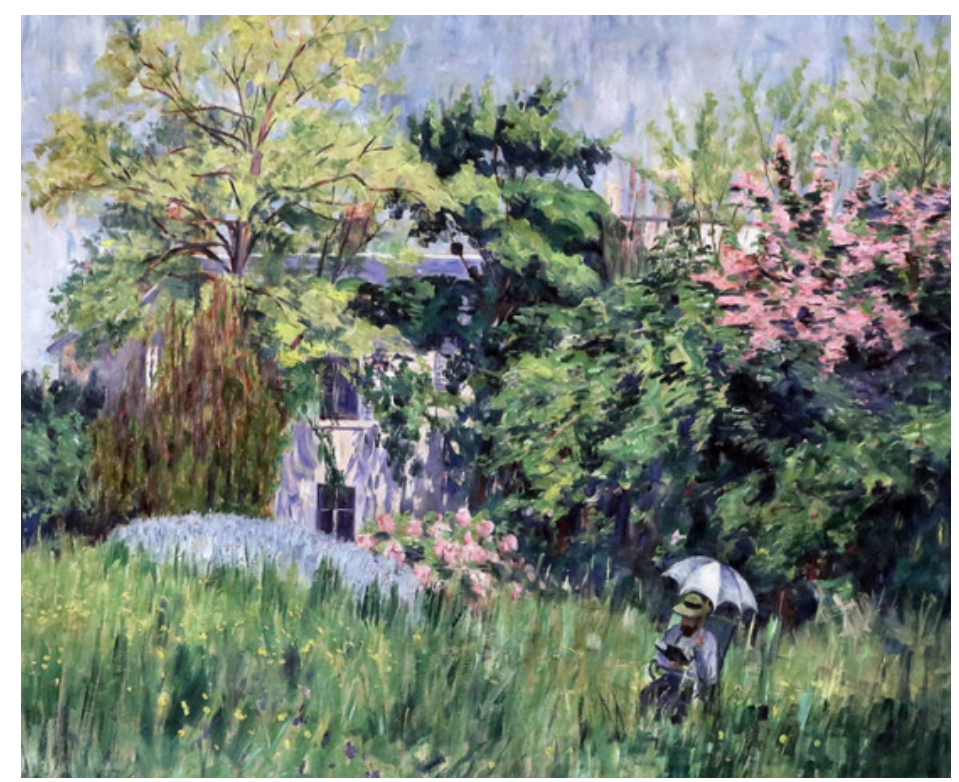

Fig. 4. Georgette Agutte. Le jardin de Bonnière. Óleo/tela, 81x100 cm.

Musée de Beaux Art. Grenoble.

la tertulia en el taller de los hermanos Zubiaurre ${ }^{36}$, y después en Madrid. Como muchos de sus colegas franceses, su estilo era impresionista, porque fijaba estados atmosféricos del paisaje, pero había en su obra una evolución a los postimpresionismos que apreció José Francés tras su exposición de óleos, aguafuertes y dibujos de sus viajes por España en el Ateneo en enero de 1917. Su pintura, "ingenua y sobria" -decía José Francés-, y sobre todo sus paisajes de los puertos gallegos y vascos (fig. 3), le hacían pensar en "Regoyos, en Iturrino e incluso en Echevarría. Y siempre bajo la obsesión francesa de los post-impresionistas, que en el último, a pesar de su personalidad, es indudable y manifiesta" ${ }^{\text {"37 }}$. Más adelante, cuando intervino en la Exposición de Santander en 1919, el crítico matizó aún más estas influencias declarando que Milada Sindlerová había: "venido a decir a Santander la buena nueva de las avanzadas del arte francés. Sobre sus paisajes aletea el genio desorbitado de Cezanne"38.

La Exposición Hispano-Francesa celebrada en Zaragoza en 1919 permitió a José Francés dar a conocer en España a Georgette Agutte (1867-1922), una pintora francesa de estilo fauvista, que acabó siendo noticia por motivos muy diferentes a las anteriores, según veremos. Se trataba de un nombre destacado de la escena francesa de principios de siglo, que había sido alumna de Gustav Moreau desde 1893, y había participado en la fundación del Salon d'Automne, donde exponía habitualmente, como también en el Salon des Indèpendants, en paralelo a Suzanne Valadon, Jacqueline Marval o Emilie Charmy y en contacto con Matisse y Rouault. Su trayectoria artística fue, sin embargo, muy corta. Casada

\footnotetext{
36 García, 2002.

${ }^{37}$ Francés, 1918a: 37-40.

${ }^{38}$ Francés, 1920c: 311.
} 


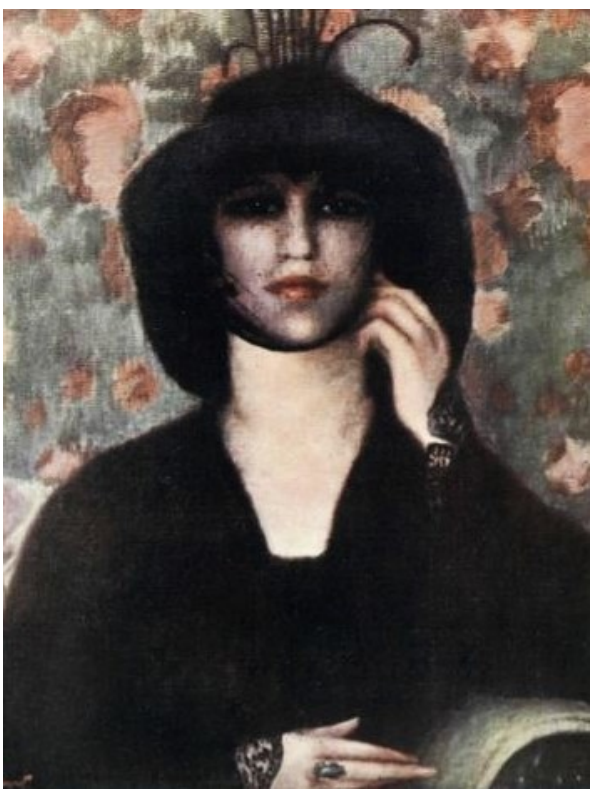

Fig. 5. Irene Narezo, La enlutada. Publicada en La Esfera (25-91915)

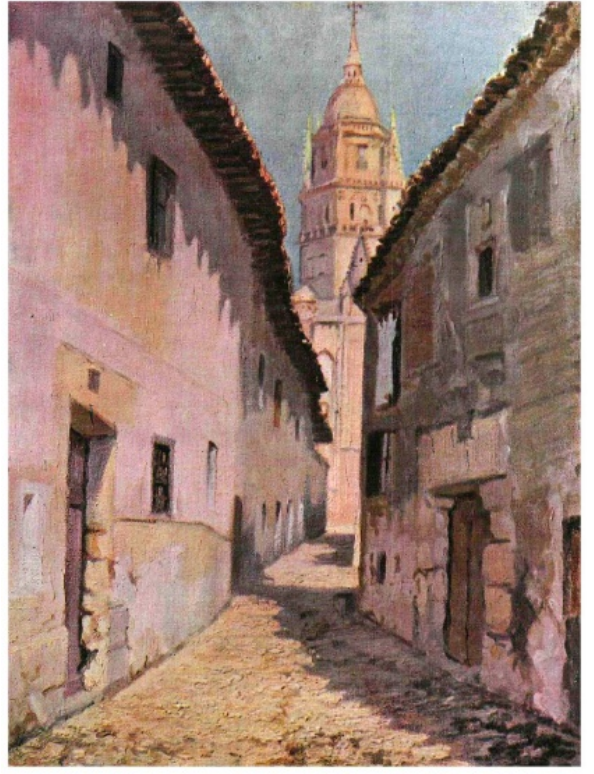

Fig. 6. María Luisa Pérez Herrero. La antigua calle del Arcediano en Salamanca. Publicada en La Esfera (28-12-1929)

en primeras nupcias con el crítico de arte Paul Flat, y en segundas con el abogado, periodista y parlamentario socialista Marcel Sembat, doce horas después de la muerte de éste en 1922, se suicidó dejando una nota de amor que conmovió a la crítica. Su obra se donó al Museo de Grenoble y tras una retrospectiva en el Salon d'Automne, organizada por el crítico de arte Gustave Kahn en 1923, se puso su nombre a una calle del distrito de Montmartre ${ }^{39}$.

Antes de que acaeciera este triste desenlace, del que José Francés se hizo eco en El Año Artístico con un texto llamado "Georgina Agutte o la fidelidad conyugal"40, el crítico ya se había interesado por la artista. Miembro organizador en la citada Exposición HispanoFrancesa y del subcomité de adquisición de obras para el Museo de Arte Moderno en dicho certamen $^{41}$, había querido traer -sin conseguirlo-, su pintura Plaza de la Bastilla. Por lo tanto, el trabajo que le dedicó fue póstumo, como homenaje a la artista y, sobre todo, como homenaje al idealismo de última decisión. Sobre su pintura apreciaba la misma mezcla "de amor antiguo y de estética nueva" sin estridencias cromáticas, que ya había celebrado en otras pintoras y, en definitiva, su interpretación delicada del paisaje (fig. 4):

"Georgina Agutte estaba situada en la moderna pintura francesa con un concepto suavemente rebelde. Sentía por los espectáculos del paisaje, por los ritmos de la forma humana, la ansiedad activa de comentarlas sin estridencias ni sin prejuicio. Así, toda su pintura es una meditación afable, atrayente, sugeridora. [...] No prefería las gamas dramáticas. No parecía tener el sentido patético del paisaje. Al contrario, el nombre de Georgina Agutte evocaba diáfanas, sutiles interpretaciones optimistas de la luz [...]" 42 .

La última pintora extranjera divulgada en las páginas de El Año Artístico era una mujer mexicana asentada en Barcelona, que tuvo su momento de gloria a raíz de su exposición de

\footnotetext{
39 Roussard, 1999.

${ }^{40}$ Francés, 1923a: 188.

41 Villalba Salvador, 2000: 160.

${ }^{42}$ Francés, 1923a: 188.
} 


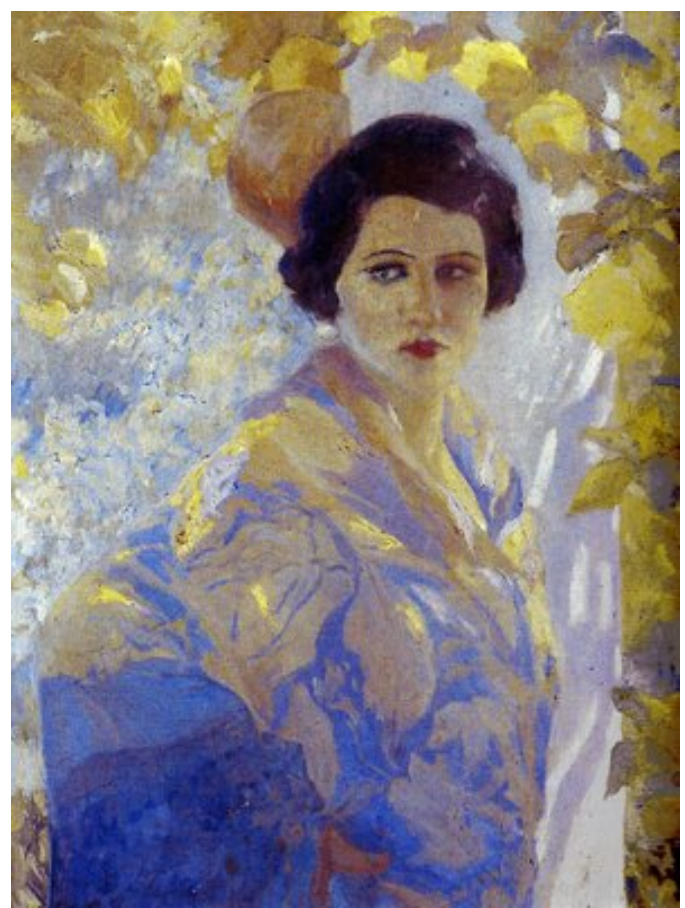

Fig. 8. María Sorolla. La chula.. Óleo/tela, 60 x $50 \mathrm{~cm}$. Museo de Bellas Artes de Valencia).

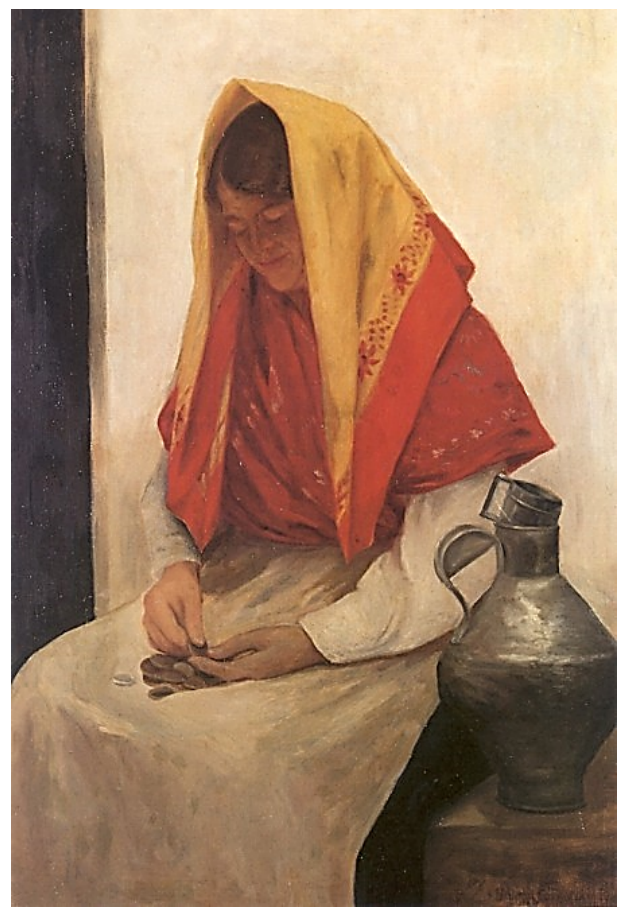

Fig. 9. María del Carmen Corredoira. La lechera. 1911. Óleo/ tela, 101 x 66 $\mathrm{cm}$. AFundación. Obra Social ABANCA

lanzamiento en la Sala Parés, en septiembre de 1915. Se trata de Irene Narezo Dragone (1905-1987), protegida de José Francés por ser la esposa de su amigo y muy admirado Federico Beltrán Massés, con quien marchó a París al año siguiente dejando de ser nombrada en la prensa artística ${ }^{43}$. El crítico le dedicó dos textos: uno para anticipar su exposición y el otro tras la misma ${ }^{44}$, resaltando en ambos la personalidad e independencia de sus retratos respecto a los del esposo. Como valores propios de la autora destacaba la ingenuidad, la sensibilidad, la emoción y cierta melancolía, presentes en obras como La Enlutada (fig. 5), que reprodujo a página completa en la revista La Esfera ${ }^{45}$.

Centrándonos ahora en las artistas españolas, la que más apoyo recibió del crítico fue la paisajista madrileña, formada en la Escuela Superior de Pintura, Escultura y Grabado de Madrid, María Luisa Pérez Herrero (1898-1934), que por estos años tenía ya una trayectoria artística reconocida, contando en su haber con varias pensiones y medallas ${ }^{46}$, todas ellas merecidísimas para el crítico, quien la siguió en su periplo expositivo hasta su temprana muerte a los 36 años. Los dos textos que publicó sobre ella en El Año Artístico fueron consecuencia de sendas exposiciones individuales en el Círculo de Bellas Artes de Madrid en 1923 y en 1925. En el primero, llamado "Una pintora paisajista" ${ }^{47}$, destacaba su capacidad para captar "la veracidad de cada sitio y cada hora" (fig. 6), de "abarcar los fugitivos matices de las cosas" y de expresar los "hallazgos sensitivos y visuales" de la naturaleza, todo ello con un brío y energía que le resultaban casi masculinos, aspecto sobre el que volveremos más adelante porque es reiterativo en muchos comentarios de Francés sobre las mujeres

${ }^{43}$ La artista envió obras desde París a exposiciones colectivas como la celebrada por la Sociedad de Artistas Ibéricos en el Parque del Retiro en mayo de 1925, abandonando después la pintura. Brihuega, 1981: 260.

44 Véase: Francés, 1916c: 213-214. Francés, 1916d: 236-238.

45 Francés, 25 de septiembre de 1915: 8-9.

${ }^{46}$ Fue pensionada en El Paular en 1919 y por la Junta de Ampliación de Estudios en Roma, Francia y Bélgica en 1923. En 1922 ganaba una tercera medalla en la Exposición Nacional de Bellas Artes.

${ }^{47}$ Francés, 1924a: 46-49. 
artistas. En el segundo, "Paisajes de Flandes por una española" ${ }^{48}$, evaluaba los trabajos realizados por la artista en su viaje por Europa, para el que había sido becada por la Junta de Ampliación de Estudios, y en él elogiaba su "cabal concepto de la personalidad y de la sinceridad artística, sacrificando incluso una parte del éxito fácil que otros pintores, menos honrados, estéticamente, logran con efectismos grotescos y extravagancias externas". Se refería, como no, al mérito de no haberse desviado con el intelectualismo del nuevo arte francés que tanto le disgustaba:

"Se ve que la joven artista no ha sufrido el -después de todo, lógico y excusable a medias- espejismo de los extravíos artísticos de la actual desorientación pictórica en Francia. Se adivina en seguida que aprovechó más el tiempo en nuevas contemplaciones solitarias de la naturaleza que lo malgastara en cenáculos, tertulias y empachos teorizantes" 49 .

Sobre esta artista, considerada por buena parte de la crítica de los años veinte y treinta como uno de los valores principales del arte de su tiempo, poco queda en la actualidad. Un estudio de Ela Rabasco ha detectado la falsa atribución de obras a su hermano Félix, caso del Paisaje de Aranjuez que cuelga en uno de los despachos del Palacio Real ${ }^{50}$.

Fuera del círculo madrileño, otra pintora que también llegó a tener cierto éxito en esta época fue la mallorquina Pilar Montaner y Sureda (1876-1971), de quien, por fortuna, existen publicadas unas memorias que revelan datos precisos sobre su vida y su obra ${ }^{51}$. En su caso, el matrimonio no fue una traba para dedicarse a la pintura; antes al contrario, su enlace con el conocido intelectual y mecenas Joan Sureda, alentó su formación pictórica y le permitió entrar en contacto y retratar a algunos de los intelectuales de la época que pasaron por su residencia de Valldemossa, entre ellos Unamuno, Rubén Darío o Eugenio D’Ors. Tampoco fue un impedimento haber sido madre de 14 hijos, cuestión que no pasó desapercibida en las críticas que generaron sus exposiciones en la Sala Parés de Barcelona y en el Círculo de Bellas Artes de Madrid en 1917 y 1918, respectivamente ${ }^{52}$.

Montaner pasó primero por una etapa romántica, influenciada por sus primeros maestros Antoni Ribas y Ricardo Anckermann, y tras recibir clases en la Academia de Bellas Artes de San Fernando y en el taller de Sorolla entre 1901 y 1904, derivó a una pintura más cercana a la estética modernista-impresionista de Mir, Rusiñol y Meifrén. A José Francés le interesaron mucho más sus paisajes, que definía como "ligeros de gradaciones, diáfanos y luminosos" que sus antiguos retratos, donde mostraba una escrupulosa lealtad de reproducción que era herencia de la copia a los maestros clásicos en el Prado. Para ella "la luz es siempre protagonista del cuadro" -aseguraba-, añadiendo que algunas vistas eran "series cromáticas a lo Manet, contemplaciones de sucesivos estados de luz sobre un mismo fondo" "54. Sin embargo, la mejor manifestación del "espíritu inquieto" y de la "febril sed imaginativa" 55 de María Montaner, la encontró José Francés en su interpretación de los olivos mallorquines, pintados con arrogancia de color y trágica expresión en telas que superaban los dos metros (fig. 7). Sobre ellos, el crítico recogía en El Año Artístico el siguiente poema de Rubén Darío:

"Los olivos que tú, Pilar pintas, son ciertos / Son paganos, cristianos y modernos olivos, / que guardan los secretos deseos de los muertos / con gestos, voluntades y

\footnotetext{
${ }^{48}$ Francés, 1928b: 206-207.

49 Francés, 1928b: 206.

${ }^{50}$ El Archivo de Patrimonio Nacional ya ha corregido la falsa atribución. Mayordomo, 2014: 40.

51 Bosch/Montaner, 2010. Peñaranda Marquès, 2006.

${ }^{52}$ Romeu, 24 de junio de 1917: 2-5.

${ }^{53}$ Francés, 1918c: 216-217 (el crítico reproducía palabras de Gabriel Alomar).

54 Francés, 1919c: 344-347.

${ }^{55}$ Francés, 1919 c: 347.
} 


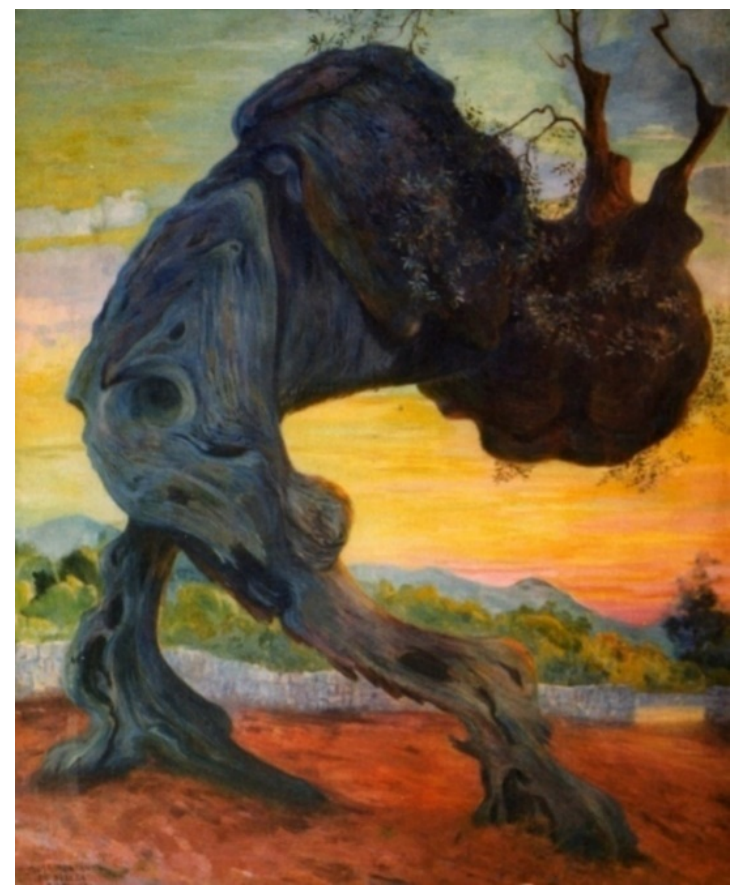

Fig. 7. Pilar Montaner de Sureda. Dolor bumano. 1921. Óleo/tela, $242 \mathrm{x}$ $197 \mathrm{~cm}$. Publicada en El Año Artístico. Octubre 1918 ).

ademanes de vivos. / Se han juntado a la tierra, porque es carne de tierra / su carne; y tienen brazos y tienen vientre y boca / que lucha por decir el enigma que encierra / su ademán vegetal o su querer de roca $[\ldots]^{\prime 56}$.

Próxima a Montaner en lo geográfico, y asimismo en lo artístico, porque se movió como ella en la estética impresionista, otra pintora que interesó a José Francés durante el período estudiado fue la valenciana María Sorolla (1890-1956). El crítico hizo un seguimiento constante de las hijas del que llamaba "el Inolvidable", quizá con más empeño sobre Elena, la escultora, de quien hablaremos más adelante. La primera vez que se refirió a ellas fue por sus envíos a la Exposición de la Juventud Valenciana de 1916, organizada por el propio Joaquín Sorolla en la capital levantina. En aquella época, José Francés reconocía en María la estela del padre y le auguraba un futuro prometedor con las siguientes palabras: "No desmiente la joven pintora su filiación artística. Este iluminismo franco, espontáneo, vigoroso, que constituye la esencia del sorollismo, estaba latente en las obras de la gentil artista, a quien seguramente aguardan muchos triunfos [... $]^{157}$. Diez años más tarde, cuando las dos hermanas expusieron juntas en el Lyceum Club Femenino de Madrid, el crítico apreciaba ya en la pintora un talento innato e independiente al del padre en sus retratos y escenas de género (fig. 8). Un talento que no llegó a tener proyección, porque abandonó la pintura para dedicarse a su marido, el también pintor sorollista Francisco Pons-Arnau:

"María realiza aquella aspiración cezanniana de pintar como el pájaro canta. Nada tan desprovisto de manera, de técnica, de factura, de trucos recetarios, de fórmulas de taller que sus notas de paisaje, sus lienzos florales y sus figuras femeninas. Se comprende una faceta nueva en el talento del padre y maestro que consintió esa lírica libertad al instinto pictórico y a la sutileza del alma. María pinta como si no hubiera tenido constante a su lado la ejemplaridad poderosa del Inolvidable, en cuanto al sistema didáctico; pero sí saturándose de ella como del aire que respiraba y la luz que entraba a iluminarla el corazón por las ventanas ávidas de los ojos. Un instinto fresco y cantarín en la atmósfera sorollesca. Esto la pintura de María Sorolla, que es grave y honda, o

56 Ibidem.

${ }^{57}$ Francés, 1917b: 252. 
alígera y optimista, según las horas, los sitios y los pensamientos, pero que siempre es veraz..." "58.

La última pintora sobre la que José Francés escribió un texto propio en las páginas de El Año Artístico, es la gallega María del Carmen Corredoira (1893-1970), formada en La Coruña por Saborit, y durante su estancia en Madrid entre 1914 y 1916, por Eduardo Chicharro y López Mezquita. Corredoira fue, posiblemente, una de las pintoras con mayor proyección de su región, y la más precoz, pues con tan solo 16 años había ganado ya una medalla de oro en la Exposición de Santiago de $1909^{59}$. José Francés, atento siempre a lo que ocurría en provincias, dejó datos precisos de su participación en varias de las Exposiciones Regionales de Arte Gallego, como la celebrada en la Coruña en 1917, la de Buenos Aires de 1920 y las del Ferrol de 1922 y 1925. Pero fue su individual en el Círculo Unión de Artesanos de la Coruña en 1925, donde expuso más de cincuenta cuadros entre bodegones, paisajes e interiores, la que propició un texto más extenso en el que recalcaba su fuerte personalidad artística, expresada en los "efectos de valoraciones atrevidas", en la "perspectiva ambiente", en la "jugosidad de matices" o en el "justo desenfoque de duras aristas" 00 presentes en sus telas. La limitación temporal de El Año Artístico no permitió a José Francés valorar su cambio temático y estilístico cuando la autora, que acabó siendo docente en la Escuela de Artes y Oficios de La Coruña, abandonó el regionalismo y sus retratos de mujeres ataviadas con trajes populares (fig. 9), para dedicarse casi exclusivamente a reflejar interiores de conventos, en particular del convento de las Capuchinas, donde pintó más de 200 cuadros, muchos de los cuales se vieron en su última exposición celebrada en La Coruña en $1966^{61}$.

\section{Cuatro escultoras}

Las escultoras que interesaron a Jose Francés durante el periodo en el que escribió El Año Artístico se movieron en los mismos parámetros figurativos que las pintoras, con cierta tendencia a la esquematización en algunos casos. José Francés solo escribió una crítica de arte de cierta amplitud sobre las mujeres escultoras: Elena Sorolla, Eva Aggerholm, Marta Spitzer y Laura Rodig, además de algún comentario corto sobre Hortensia Begué, esposa de Celso Lagar, cuando expuso con él en el Ateneo de Madrid en 1918.

Esta diferencia numérica entre pintoras y escultoras en El Año Artístico no se debe a un desinterés del crítico por la especialidad, sino a la excepcionalidad de dicha ocupación entre las artistas españolas de la época, dadas las barreras sociales y morales de su práctica femenina. Sirva de referencia saber que entre 1900 y 1936 sólo se presentaron a la Exposición Nacional de Bellas Artes un total de 28 escultoras, y sólo 4 lo hicieron en el Salón de Otoño entre 1920 y 1935. Dificultaban su práctica, además de los prejuicios sobre la fuerza física necesaria y una idea estereotipada de lo que era o no femenino, la existencia de relaciones sociales para buscar mecenazgo, la necesidad de un taller con espacio suficiente, que era difícil tener en el propio domicilio y a veces había que compartir, así como una economía solvente para la compra de materiales ${ }^{62}$.

Volviendo a la familia Sorolla, de la escultora Elena Sorolla (1895-1975), formada en los talleres de Benlliure y Capúz, José Francés señaló en un primer momento, a tenor de sus envíos a la citada Exposición de la Juventud Valenciana, que sus bustos estaban modelados con mucho brío y con un moderno sentido decorativo, digno de alabanza ${ }^{63}$. Más adelante insistía en lo mismo sobre un torso presentado en la Exposición Nacional de Bellas Artes de

\footnotetext{
${ }^{58}$ Francés, 1928c: 424.

${ }^{59}$ Pereira Bueno, 2004: 78 y 156. El libro traza el recorrido de la autora por todas las exposiciones regionales gallegas, abordando también su recepción crítica.

${ }^{60}$ Francés, 1928a: 167.

61 Villarde Solar, 2009.

62 Véase.: Barrionuevo, 2006a. Barrionuevo, 2006b: 46-56.

${ }^{63}$ Francés, 1917b: 252.
} 


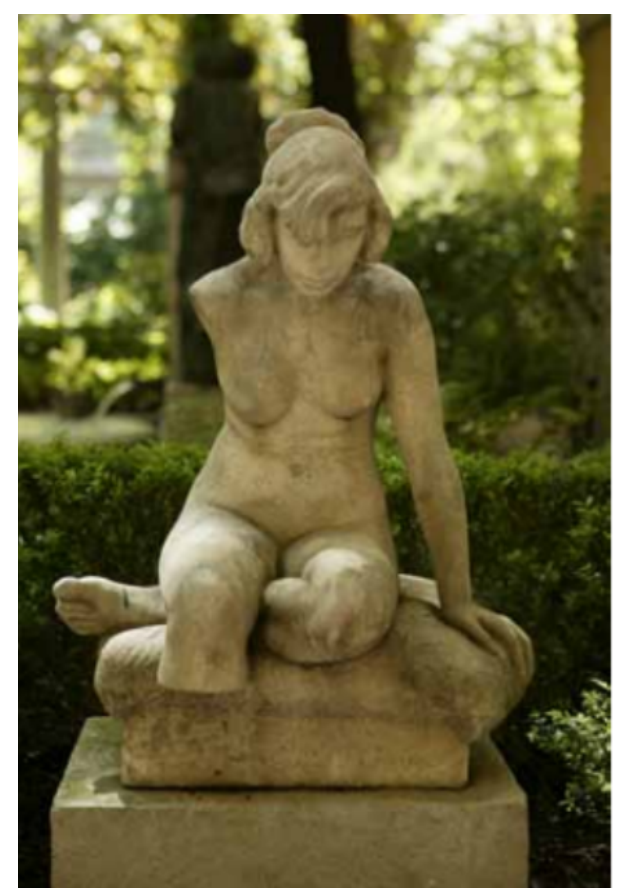

Fig. 10. Elena Sorolla, Mujer sentada 1919. Fundación Museo Sorolla

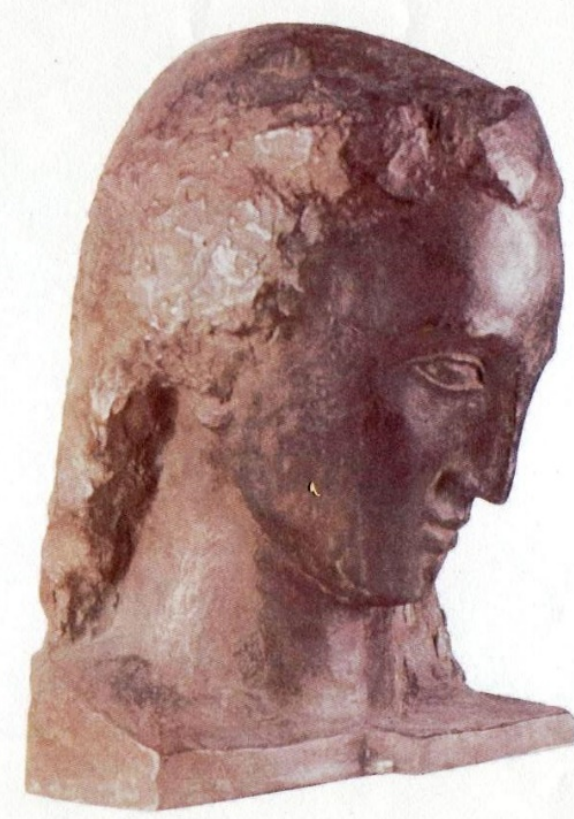

Fig.11. Eva Aggerholm. Cabeza de muchacha. 1948. Bronce patinado. MNCARS

1920, del que decía estar resulto "de un modo tan firme, sin alejar la idea de una romántica riqueza sentimental" " ${ }^{4}$. Cuando expuso junto a su hermana en el Lyceum Club en 1926 fue algo más explícito. A Elena le reconocía más habilidad técnica que aquélla, pero el mismo talento innato y la misma veracidad estética y espontánea interpretación, sin postizos ajenos ${ }^{65}$. La autora, que había recibido, como su hermana, una formación progresista en la Institución Libre de Enseñanza, se atrevió también con desnudos en fechas en que el decoro hacía evitar esta temática en las mujeres (fig. 10), y al igual que aquélla, abandonó pronto la escultura. Actualmente, algunas de sus obras pueden verse en el Museo de Sorolla, que organizó una exposición temporal sobre la artista para conmemorar el día de la Mujer en 2015 y ha editado un monográfico que explica su vida y aporta claves interpretativas sobre su obra ${ }^{66}$.

Coincidiendo en muchas exposiciones con Elena Sorolla, José Francés también trazó el recorrido expositivo de una escultora que acabó formando parte de la Asociación de Artistas Ibéricos $^{67}$, la danesa Eva Aggerholm (1879-1959), aunque fue su exposición en el Museo de Arte Moderno de Madrid en 1921, junto a Daniel Vázquez Díaz, su esposo, la que motivó un texto de cierta envergadura ${ }^{68}$. En él reconocía influencias nórdicas, de donde procedía su ancestral espiritualidad y su misticismo; y como resultado de formación en París, influencias de Bourdelle. Para José Francés, las notas genuinas de la escultora eran el sentimiento, la emotividad y el reposo, visible en obras como Monumento a los padres, Magdalena, Dolor, Pureza, etc. (fig. 11). Sobre este último aspecto, y contradiciendo a Juan Ramón Jiménez, que había

${ }^{64}$ Francés, 1921d: 247-248.

${ }^{65}$ Francés, 1928c: 424.

66 Almarza, 2013

${ }^{67}$ Expuso con la Sociedad de Artistas Ibéricos en Copenhague (1932), Berlín (1933) y París (1936). Pérez Segura, 2003: 111, 117, 124, 141-143, 218, 217. Sobre Eva Aggerholm véase: Barba Robles, 2000.

${ }^{68}$ Francés, 1922: 77-79. 
relacionado la escultura de Aggerholm con la energía de las olas del mar llamándola “marinera de la escultura" "69, José Francés aseguraba que Eva Aggerholm era calma...

“...reposo, éxtasis, ternura y dolor, sencillamente entregados a su emotividad. Las esculturas de Eva Aggerholm fijan estados anímicos con una calma fervorosa de oración y con esa fuerza latente y quieta de los verdaderos trozos arquitectónicos [...]. Un arte noble, hondo y armonioso, que va creando una mujer dotada de extraordinaria sensibilidad, como si compusiera versos, como si imaginara edificios para la meditación, el éxtasis y el amor reflexivo"70.

La huella de Bourdelle, de Maillol y de Bernard, estaban también en la obra de la escultora francesa Marta Spitzer (1877-1956), otra de las artistas extranjeras asentadas en España en los años de la Guerra Mundial, cuya exposición de bronces en el Salón Lacoste en noviembre de 1917, fue para el crítico de las que "merecen los elogios y de las que compensan y desquitan de otras anteriores y recientes" "71. En este caso, lo que más llamó la atención del crítico no fue solo su sensibilidad o el "amor a los cánones antiguos, a los ritmos augustos y eternos, a la solemne calma clásica", que hacían un "reto de pureza y de espiritualidad contra el aburguesamiento artístico de los rezagados y contra la extravagancia fácil de los arribistas y los imparciales"; también consideró ejemplares sus aciertos de ejecución, su vigor, su vitalidad y una técnica que encontraba "casi viril", juicio este último muy común en los textos dirigidos a escultoras ${ }^{72}$. Durante estos años la artista estaba todavía estaba en formación, y ejecutaba bronces pequeños al estilo de Muchacha oriental (fig. 12), Joven Criollo, etc., llegando a tener en 1932 encargos monumentales como La Pietà de la Grotte de Sainte-Marie-Madeleine, en la Provenza.

La última escultora que mereció titular en El Año Artístico fue una artista chilena que estaba de paso por Madrid en 1924. Se trata de Laura Rodig (1901-1972), que exponía dibujos y esculturas en el Salón Nancy junto al pintor argentino José Antonio Terry. Rodig se había formado en la Escuela de Bellas Artes de Santiago en los años en que fue director Fernando Álvarez de Sotomayor, institución de la cual recibió una beca de formación en Europa que la sitúa en la Academia de André Lothe en París, en Italia y en España. Sus viajes a México junto a Gabriela Mistral, de quien fue secretaria y compañera sentimental por un tiempo ${ }^{73}$, fueron la fuente de inspiración de una obra de marcado indigenismo y carácter social, que llegó a tener cierto renombre en su país, donde fundó la Asociación de Pintores y Escultores de Chile en 1930 y recibió el Premio Nacional de Bellas Artes en 1949, dedicándose también a la enseñanza. En España, algunas fuentes la sitúan erróneamente en el Museo de Arte Moderno $^{74}$, al haber adquirido la institución, tras ser premiada por el círculo de críticos en Madrid $^{75}$, su obra India mexicana (fig. 13), que actualmente conserva el MNCARS. José Francés vio en lo que todavía le parecían "tentativas escultóricas", una excelente promesa, pero mostró más interés por la temática exótica y orientalizante de sus indias, "de mirada enigmática de ojos almendrados y misteriosa tristeza en rostros angulosos" "76, que por su técnica, que le resultaba demasiado monótona y presta a estancarse en la facilidad de manera. Años después de finalizar El Año Artístico, la artista estaría nuevamente de actualidad en España, donde obtuvo una Medalla de Oro en la Exposición Iberoamericana de Sevilla en

\footnotetext{
${ }^{69}$ Citado en: Crespo, 1999: 221.

${ }^{70}$ Francés, 1922: 77.

71 Francés, 1918d: 387-389.

72 Sobre la crítica a las escultoras españolas durante el mismo período, véase: Rodrigo Villena, 2018: 145 -

73 Valdebenito Carrasco, 2018: 242.

74 Cortés Aliaga, 2013: 180.

75 Valdebenito, 2018: 228.

76 Francés, 1925: 417-420.
} 168. 


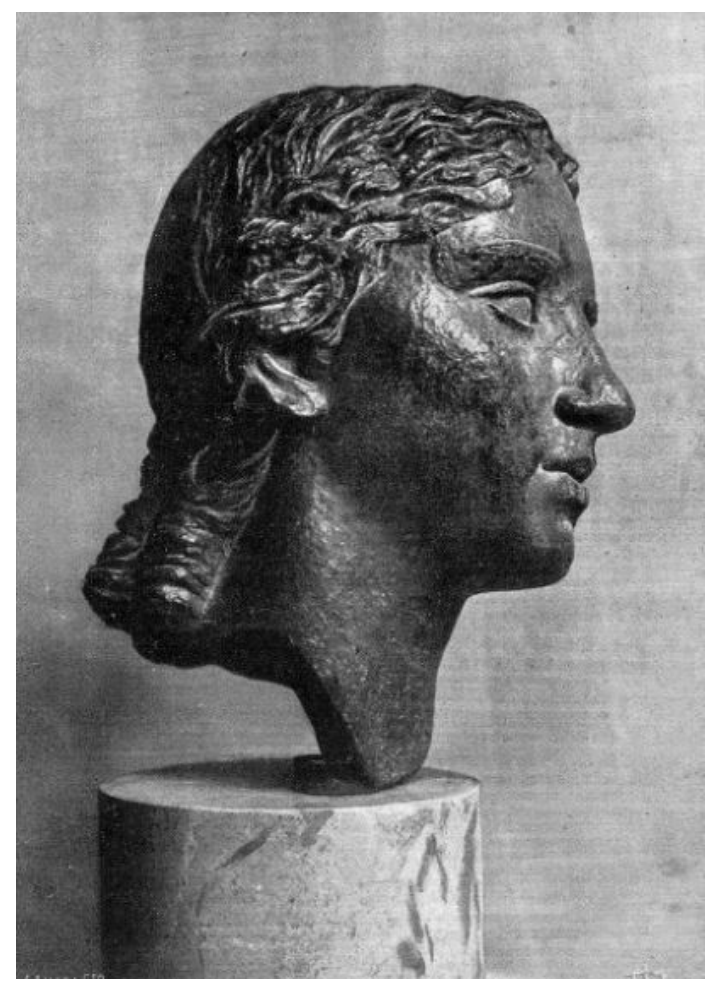

Fig. 12. Marta Spitzer, Muchacha oriental. Bronce. Publicada en La Esfera (8-12-1917

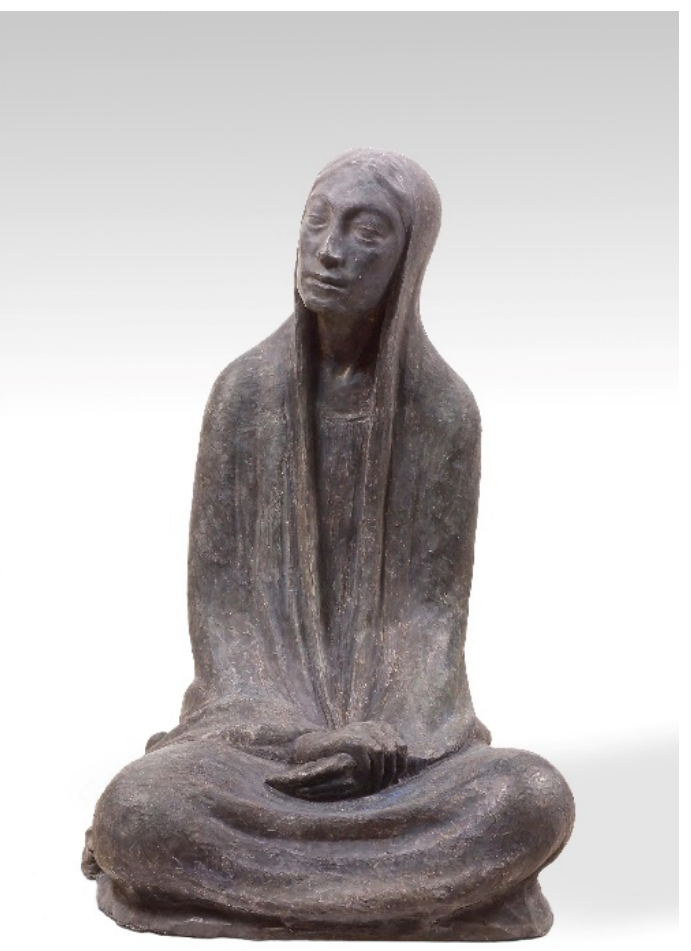

Fig. 13. Laura Rodig. India mexicana. Vaciado en escavola patinada, 1924. MNCARS

1930. Sabemos también que participó en la construcción del movimiento feminista en su país, y que desde allí impelió a sus compatriotas a solidarizarse con las españolas durante la Guerra Civil, dando su apoyo a la causa republicana ${ }^{77}$.

\section{Prejuicios de género en la crítica de José Francés.}

Más allá del respeto que José Francés demostró tener a las artistas que despertaron su interés, las páginas de El Año Artístico reproducen todos y cada uno de los tópicos sexistas presentes en la sociedad de su tiempo sobre este colectivo ${ }^{78}$. Entre los de menor trascendencia, siguiendo las directrices de la crítica finisecular analizada por Estrella de Diego $^{79}$, hallamos en sus textos resquicios del lenguaje galante, con abuso de expresiones del tipo "la gentil" o "la gentilísima artista", que podrían resultar inocentes en un modelo de crítica tan lírico y tendente a la efusión retórica como fue la suya, pero no dejan de ser exponentes del nefasto abuso de la cortesía y del paternalismo sobre las mujeres $\operatorname{artistas}^{80}$, o del también recurrente juicio sobre el aspecto físico de las mismas. No debemos pasar por alto que el concepto "gentil" referido a lo amable, noble, educado o cortés, tiene un doble sentido relativo al aspecto físico, y a veces era lanzado como un piropo que incidía en la belleza, elegancia, gracia o lozanía de la artista señalada. De hecho, sin ser recurrente, José Francés se refería en algunas críticas a la belleza de las autoras ${ }^{81}$. Por ejemplo, de Irene

\footnotetext{
77 Barchino, 2013.

78 Sobre la crítica a las mujeres artistas en este periodo, véase: Rodrigo Villena, 2017a: 1242-1256.

${ }^{79}$ Diego, 1987: 317-370.

80 Greer, 2005: 69-88.

81 Rodrigo Villena, 2017a: 1245. Rodrigo Villena, 2017b: 149 y 151.
} 
Narezo, decía haber escrito el catálogo de su primera exposición: "como un homenaje a su talento y á su belleza" 82 .

Otra herencia del pasado, que había sido casi una obsesión en el siglo XIX ${ }^{83}$ y todavía está presente en la crítica de José Francés, es cierta intención de agrupamiento de las artistas por el simple hecho de ser mujeres. Aunque no se produce en todos las críticas, en algunas exposiciones colectivas el crítico hablaba de las artistas como grupo marginal, o las dejaba para el final, citando sólo sus nombres, al modo del siguiente párrafo que cerraba la crónica del VI Salón de Humoristas de 1920: "Finalmente, al VI Salón de Humoristas han concurrido, como a los anteriores, varias expositoras con Pepita Sagañoles al frente, y entre las cuales se deben citar las señoritas de Martí Alonso, Ascensión Fernández Cuervo, Luisa Rubio [... $]^{\prime 84}$.

De mayor trascendencia son algunas descalificaciones o burlas que hoy se perciben con cierto tinte misógino. Por ejemplo, en el artículo que publicó sobre Rosa Bonheur (18221889), que para él era una artista de segundo orden y, por lo tanto, no debía haber formado parte de la Exposición de Pintores Franceses celebrada en Parque del Retiro de $1918^{85}$, José Francés relacionaba a la pintora con dos mujeres que le desagradaban por motivos sexistas opuestos: la Georg Sand de los últimos años, vestida de hombre como Bonheur, a quien recriminaba su actitud libre y moderna llamándola: "enfadosa devoradora de Musset y de Chopin"; y la pintora danesa Enriqueta Ronner, también animalista, a la que, por el contrario, tachaba de cursi y anticuada "por sus empalagosos y solteroniles cuadros de perros y gatos"

La necesidad de comparar a unas mujeres con otras y el tratamiento de excepción que el crítico otorgó a sus artistas preferidas, desvelan a su vez cierto desprecio hacia la generalidad del arte femenino, algo que compartía con los críticos de su generación, derivado seguramente de la mala imagen que se tenía de las artistas burguesas de afición, aunque para las fechas en que José Francés escribe y publica El Año Artístico, este modelo estaba siendo sustituido por el de pintora profesional. Una de sus artistas más admiradas y destacadas sobre el resto fue la decoradora, dibujante e ilustradora Aurora Gutiérrez Larraya (1880-1920), a quien recordaba como "un compañero cordial y efusivo de este grupo romántico, indisciplinado y generoso de los dibujantes españoles" ${ }^{\prime \prime 7}$ cuando le sobrevino la muerte a los 40 años. Por su perfil polifacético, la artista encajaba perfectamente en los Salones de Humoristas creados por José Francés en 1914, y en la tertulia de los Humoristas del Café Jorge Juan, donde se alentaba la ilustración editorial, las artes decorativas, el dibujo y la caricatura $^{88}$. Gómez de la Serna la recordaba también en el Pombo ${ }^{89}$, junto a su hermano Tomás, con el que expuso y realizó trabajos colectivos en muchas ocasiones. José Francés escribió críticas conjuntas sobre ellos, que resaltaban la maestría y el espíritu "inquieto, dinámico, insatisfecho siempre por su sed de renovación espiritual y de nobleza artística" "90, de ambos. Pero también dedicó muchas líneas a Aurora en solitario, elevándola siempre al prototipo de artista cultísima, de espíritu refinado y caso verdaderamente inusual frente a un panorama del arte femenino que le parecía desolador:

"Aurora Gutiérrez Larraya es una artista cultísima [...]. En todas las Exposiciones Nacionales sus envíos se han destacado con mucho del de otras señoritas que aún creen es arte decorativo vestir de "boy-scout" a una muñeca ó bordarle unas zapatillas a su papá. Y no sólo se destaca la señorita Gutiérrez Larraya sobre esas señoritas tan españolamente cursis. Al fin y al cabo eso no sería gran mérito. En la última Exposición

\footnotetext{
82 Francés, 1916d: 236.

83 Diego, 1987: 152.

${ }^{84}$ Francés, 1921a: 47.

${ }^{85}$ Francés, 1919c: 155 y 166.

${ }^{86}$ Francés, 1919d: 166-170.

${ }^{87}$ Francés, 1921c: 183.

88 Villalba Salvador, 2001: 371.

${ }^{89}$ Gómez de la Serna, 1986: 144-145

${ }^{90}$ Francés, 1919a: 97-98.
} 
de Arte decorativo, [...] acaso fueran los envíos de Aurora Gutiérrez Larraya los que nos hicieron vislumbrar un porvenir lógico, bien orientado, al arte decorativo español"91.

Este texto, común a otros similares que pueden leerse en El Año Artístico, expresa la percepción general que tenía José Francés sobre el arte femenino, que consideraba afectado, cursi ("las artes ñoñas de las señoritas españolas" - decía en otra ocasión-) y de mala calidad. Los atributos típicamente femeninos que José Francés encontraba en pintoras y escultoras eran, tanto en temas como en estilo: la ingenuidad, la sensibilidad, la delicadeza, la gracia, la ternura, el encanto o la simpatía ${ }^{33}$, que el crítico expresaba en juicios como: "De nuevo el arte ingenuo nos seduce" ${ }^{94}$, referido a Victoria de Malinowska; "dibujos encantadores por la riqueza imaginativa y por la ingenuidad de su procedimiento" ${ }^{95}$, referido a la dibujante Lola Anglada; o "cuadros y dibujos llenos de belleza y de ingenuidad" "96 sobre Irene Narezo. Dichos atributos femeninos del arte le agradaban en la misma medida que le resultaba simpática la frescura de las obras primerizas de cualquier artista joven, pero no eran para el crítico suficientes si los comparaba con las grandes cualidades - masculinas- del arte, que eran para él: la elocuencia y la inteligencia, la maestría técnica, la sobriedad, la seguridad, el vigor del dibujo o la fuerza del colorido. Por ello, las artistas que recibieron mejores críticas en El Año Artístico eran para él artistas excepcionalmente viriles, que poseían y trasladaban a sus obras méritos impropios de su sexo. Entre todas ellas, el caso más excepcional fue para José Francés el de la citada María Luisa Pérez Herrero. Así lo explicaba él mismo en el anuario:

"La señorita Pérez Herrero no es el turista mercantil del paisaje. Es, por el contrario, un espíritu ávido de belleza que emplea la naturaleza para expresar sus hallazgos sensitivos y visuales. El viejo Degas, que odiaba a la pintora, y el viejo Huysmans que odiaba a la escritora, tendrían que sonreír, desarmados de su obsesión, el uno ante los cuadros de Berta Morisot y el otro frente a las novelas de Miriam Harry.

Claro que en el fondo el motivo sería el mismo. La extraña y valiosa calidad viril del temperamento y de la técnica. Porque María Pérez Herrero "pinta como un hombre", se ha dicho demasiadas veces. Como un hombre que no alimentase su secreta deformidad sexual, su melancolía afectada por no ser mujer. Así hay muchos hombres que pintan... y se pintan.

La señorita Pérez Herrero, es decir, el arte de la señorita Pérez Herrero tiene un acento varonil, una seguridad varonil, una varonil elocuencia. No se sabría definir exactamente con las palabras en qué consiste ese carácter de masculinidad del Paisaje, pero lo cierto es que existe. Otras pintoras (evitemos alusiones directas) se ve enseguida que pintan como su mamá bordaba relojeras y zapatillas, o una hermanita suya hace encajes de bolillos"97.

Otras artistas que habrían ennoblecido su estilo femenino añadiendo a su obra elementos viriles, fueron: Rosa Bonheur, de la que decía que "pinta con el vigor de un hombre y siente con el espíritu de una mujer, muy mujer" "; la escultora Marta Spitzer, cuya "sensibilidad claramente femenina ennoblece el dominio viril de la factura" "99; la pintora Pilar Montaner,

\footnotetext{
91 Francés, 1916b: 55-56.

${ }^{92}$ Francés, 1921d: 255.

93 Esta forma de sojuzgar a las artistas ha estado presente en la crítica de arte hasta los años setenta del siglo pasado. La introducción de la llamada "ginocrítica", identificó el sexismo en la cultura visual como mecanismo de dominación estructural del patriarcado. Véase: VILLA, 2013: 10-23.

94 Francés, 1919g: 356.

${ }^{95}$ Francés, 1917a: 18.

${ }^{96}$ Francés, 1916c: 213.

${ }^{97}$ Francés, 1924a: 46-49.

98 Francés, 1919d : 169.

${ }^{99}$ Francés, 1918d: 389.
} 
cuya pintura era "recia, vigorosa, reveladora de un temperamento casi varonil" ${ }^{100}$; la acuarelista portuguesa Helena Gameiro, en cuyas pinturas de flores encontraba "una viril afirmación de energía cromática" ${ }^{101}$; aspecto repetido en las críticas a la gallega María del Carmen Corredoira, quien con la "energía de su fuerte temperamento de pintor", y su "factura varonill", habría rechazado "las acarameladas acuarelas de pájaros y flores" 102 comunes en el arte femenino vulgar, etc.

\section{Balance final.}

Tras una exhaustiva revisión de las páginas de El Año Artístico de José Francés que ha revelado nombres y cifras precisas de mujeres artistas y especialidades practicadas, así como datos cualitativos sobre su percepción particular del arte femenino y del papel de la mujer artista en el contexto de la polémica de los géneros, resulta difícil a día de hoy concluir si fueron pocas, muchas y suficientes las artistas divulgadas, o si la postura del crítico fue favorable o no a la profesionalización de la mujer artista. Quisiera, por ello, destacar algunos aspectos reveladores, antes de hacer un balance final.

Como se ha dicho, los años en que José Francés escribió y publicó El Año Artístico (19151926) fueron años de profesionalización femenina, marcados por la polémica de los géneros planteada tras la Guerra Mundial y el desarrollo del feminismo. Su postura particular en estas cuestiones fue similar a la de otros intelectuales "progresistas", que miraban con optimismo los nuevos roles de la mujer, pero no acababan de asimilar los cambios, ni de renunciar a las ventajas que les confería la sociedad patriarcal.

Lo apreciamos sobre todo en los textos escritos por José Francés en La Esfera en los años más próximos a la guerra. Sobre las consecuencias del conflicto mundial para la mujer y la sociedad, José Francés reconocía en la guerra "una aliada del feminismo" ${ }^{103}$, que había favorecido un avance femenino legítimo e innegable, demostrando "que una mujer vale para todo" 104 , e incrementado el número de mujeres "que destacaban en la literatura, en la ciencia, en el arte, incluso en otras manifestaciones intelectuales" ${ }^{105}$. Pero frente a estos logros justos, el crítico consideraba nefastas todas las actividades que alejaban a las mujeres de sus encantos naturales (sensibilidad, elegancia, etc.) y de su vocación de amor y ayuda al hombre ${ }^{106}$, rechazando con vehemencia las incursiones femeninas en la guerra, sus trabajos para las fábricas de municiones, o la defensa acérrima y poco elegante de sus derechos, al estilo de "las furias grotescas de la señora Pankurst" ${ }^{107}$, según él mismo escribía.

Vemos también esta diatriba entre las nuevas y viejas ideas sobre la mujer en textos que reconsideraban la participación femenina en asuntos artísticos. Así, sobre los cambios que la nueva distribución de roles estaba generando en el sistema del arte, tan triste y grotesca le resultaba la estampa de los hombres ocupándose de las fábricas de bordados en Bélgica, que antes regentaban "las belgas, silenciosas y felices bajo sus cofias de encaje" 108 -escribía-, como sugerente la estampa de "una linda girl contemporánea" ocupando el puesto de vigilante de exposición o de Museo, como ya se veía en Londres, aunque allí -decía el crítico con poca elegancia y el citado resquemor hacia el feminismo inglés-: "ahora sólo entran las feas y se procura desfeminizarlas con trajes antiestéticos" 109 .

Más allá de estos prejuicios, que se irían suavizando con el paso de los años, la realidad es que José Francés fue sensible y alentó la emancipación intelectual y artística de la mujer, poniéndose del lado de algunas mujeres criticadas en la época por invadir espacios

\footnotetext{
100 Francés, 1919e: 344.

101 Francés, 1924b: 167.

102 Francés, 1928a: 167.

${ }^{103}$ Francés, 31 de julio de 1915: 19.

104 Francés, 19 de agosto de 1916: 29.

105 Ibidem.

${ }^{106}$ Francés, 13 de octubre de 1917: 21.

107 Ibidem.

${ }^{108}$ Francés, 17 de julio de 1915a: 29.

${ }^{109}$ Francés, 17 de julio de 1915b: 29.
} 
masculinos. Un ejemplo fue la gran admiración que sintió por una de las precursoras de las modernas más vilipendiada de su tiempo: Emilia Pardo Bazán, tachada de libertina y atea por defender el naturalismo de Zola, de feminista por su apología de los derechos de la mujer, y de marimacho por escribir y alcanzar el éxito con un estilo literario considerado varonil ${ }^{110}$. En cambio, para José Francés, que utilizaba en La Esfera el pseudónimo "Silvio Lago", protagonista de La Quimera de Pardo Bazán, la escritora era "uno de los novelistas más grandes de Europa" "111, reconociéndole también su labor como crítica del arte e impulsora del renacimiento del encaje en España:

\begin{abstract}
"Iba y venía por entre las vitrinas como va y viene por entre la literatura de todos los países, dotada de una autoridad y de un prestigio indiscutible. Ella, tan culta en materia literaria, autora de tal número de libros admirables que imponen su nombre al mundo con una solidez no alcanzada por muchos escritores masculinos, aparecía como una obrera más en medio del conjunto de femeninas obras. Y disertaba acerca de ellas con charla amenísima y documentada"112.
\end{abstract}

También expresa su interés hacia el talento y la posición de las mujeres que ejercían papeles poco convencionales en la época, su cercanía a la periodista y escritora Carmen de Burgos, a cuyas tertulias acudía según lo narrado por Cansinos Assens ${ }^{113}$; o su defensa del Lyceum Club de Madrid, una institución y sus socias (lo dirigía María de Maeztu, siendo vicepresidentas Isabel Oyarzábal y Victoria Kent, y secretaria Zenobia Camprubî) criticadas desde diferentes sectores conservadores como desertoras del hogar, criminales, ateas, excéntricas y desequilibradas ${ }^{114}$.

Sobre este espacio cultural, que fue lugar donde reunirse, intercambiar ideas y organizar actividades de tipo artístico, social, literario, científico, etc. pero también plataforma para potenciar la emancipación de la mujer, José Francés se mostró complaciente y lo defendió como lugar necesario en una ciudad que consideraba ya preparada para la emancipación de la mujer, avalado por el "prestigio inteligente de sus fundadoras" "115; postura muy diferente a la de otros intelectuales que se negaron a ir, caso de Benavente, o a los que aprovecharon sus visitas para burlarse de ellas, como hizo Rafael Alberti cuando quiso comprobar la "últimamente cacareada inteligencia del bello sexo" "116 , burlándose intencionadamente de los autores de la Generación de 98.

José Francés también ensalzó el Lyceum por sus actividades artísticas, que dirigía Carmen Baroja. Transcurrido algo más de año desde la primera exposición inaugurada por las hermanas Sorolla, el crítico escribía en La Esfera que ya habían pasado por su salón muestras tan interesantes como los batik y cueros repujados de Victorina Durán y Matilde Calvo Rodero, los lienzos modernos de Marisa Roësset, el arte de Aida Uribe, los dibujos de la argentina María Elena Ramírez, las caricaturas de Romà Bonet (Bon), etc. Para el crítico, la organización de esta última exposición demostraba de "modo muy directo el nivel intelectual de la flamante Sociedad"117.

$\mathrm{Y}$ a pesar de estos gestos hacia a las mujeres intelectuales y artistas, e incluso del rechazo explícito en sus textos de las posturas misóginas de Moebius, Schopenhauer ${ }^{118}$, Degás o Hyusmann ${ }^{119}$, José Francés asumió y reprodujo en las páginas de El Año Artístico muchos de los prejuicios sobre la inferioridad creativa de las mujeres, divulgados por las teorías de la

\footnotetext{
110 Mangini, 2001: 42-47.

111 Francés, 1918 c: $352-353$.

112 Francés, 1920b: 222 y 229.

113 Cansinos Asssens, 1982: 364-365.

114 Mangini, 2006: 126.

115 Francés, 1928c: p. 422.

116 Citado en Mangini, 2006: 91-92.

117 Francés, 2 de julio de 1927: 21.

118 Francés, 31 de julio de 1915: 19.

119 Francés, 1924a: 48.
} 
diferenciación de los sexos (Nordau, Novoa Santos, Marañón, Ortega y Gasset, Simmel, etc.), siendo los más evidentes, según se ha dicho: la cualidad viril que atribuía a las artistas que poseían valores contrarios a lo esperado por las mujeres, y la idea de un arte femenino cursi y afectado; prejuicios, por otro lado, presentes en todos los críticos de arte, incluidas las mujeres que ejercieron la profesión en el mismo período ${ }^{120}$.

Estas y otras argucias de la sociedad patriarcal para frenar la irrupción de la mujer en el arte y su emancipación en la sociedad, explican en gran medida el silencio y la desatención generalizada hacia las mujeres artistas en la crítica de arte de la época. Un vacío del arte femenino que en el caso de El Año Artístico, y según lo dicho del autor, parece no haberse producido.

En cambio, hay que considerar que aunque la revista haya aportado la cifra aparentemente halagadora de 175 mujeres artistas diferentes, este número es absolutamente irrelevante en comparación con las listas interminables de autores masculinos a las que el crítico aludía cada año en una obra de la envergadura de la suya; y mucho más si tenemos en cuenta que casi todas las artistas fueron simplemente citadas en una sección llamada "Memoranda", que localizaba a artistas en diferentes eventos sin generar una crítica de arte sobre su obra. A esto debemos añadir que casi ninguno de los 13 trabajos que José Francés escribió sobre las 14 artistas citadas (recordemos que sobre María y Elena Sorolla escribió solo un texto conjunto) fueron textos largos que ocuparan varias páginas, como sí sucedía para los grandes nombres masculinos del arte, y que algunos se reducen apenas a unas líneas. Por otro lado, se debe considerar que de las 175 artistas citadas en la publicación, solo 114 practicaban las especialidades de más prestigio, nombrando a 108 pintoras y a 6 escultoras; de modo que fue la sensibilidad del crítico hacia las artes decorativas (gremio en el que cita a 38 mujeres), el seguimiento de los dibujantes en los Salones de Humoristas (nombra a 20 ilustradoras, grabadoras o caricaturistas), y a más aún, su interés por el arte de los extranjeros en España o de los salones parisinos, los que han permitido recuperar un número mayor de mujeres artistas en El Año Artístico, respecto a otras revistas de su tiempo.

Por lo tanto, podemos concluir que José Francés no planteó en su anuario el tema de la mujer artista como fenómeno social, ni reivindicó su papel en el arte, algo que se empieza a notar en la década siguiente, cuando exposiciones de éxito como la de Maruja Mallo en la Revista de Occidente en 1928, Marisa Roësset en el Museo de Arte Moderno en 1929, o Ángeles Santos en el Salón de Otoño en 1930, permitieron a la crítica identificar una nueva generación de pintoras y escultoras más formadas y competitivas que sus predecesoras, fruto de los avances del feminismo, pero también de la mayor receptividad social del gobierno de la República ${ }^{121}$. La recuperación de nombres femeninos, todos ellos en una línea que se despegaba del academicismo hacia los impresionismos o postimpresionismos fue, en su caso, resultado de una escrupulosa y enciclopédica visión del arte de su tiempo y no fruto de un proyecto intencionado de integración de la mujer en el ámbito artístico.

Con todo, debe reconocerse en El Año Artístico (1915-1926) un archivo imprescindible para recuperar a muchas de las artistas silenciadas por la historiografía artística posterior; sobre todo a las no vanguardistas, menos estudiadas y presentes en la bibliografía. Téngase como referencia, y sea de justicia para terminar, contrastar el número de mujeres presentes en el anuario de José Francés, respecto a las que se citaron en otras revistas especializadas, caso de Arte Español, en la que solo se nombra a 7 mujeres artistas entre 1910 y 1935. Bien es cierto que en dicha publicación prevalecían los trabajos historiográficos sobre las crónicas de actualidades, pero en las descripciones de las exposiciones organizadas por el grupo al que representaba -la Sociedad Española de Amigos del Arte- y en sus crónicas de las Exposiciones Nacionales de Bellas Artes, el único que recuperó algunos nombres fue Luis García de Valdeavellano, obviando otros críticos (Margarita Nelken, Joaquín Ciervo, Cristina de Arteaga, Pedro G. Camio) la participación femenina.

120 Véase: Muñoz, 2012: 393-413.

121 Lomba, 2015: 599-516. 


\section{Bibliografía:}

Almarza, F.: Elena Sorolla García, Escultora. Valencia: Museo Sorolla. (2013).

Allende, M.: "Laura Rodig. Cabeza". En: Catálogo razonado. Colección MAC. Santiago: Museo de Arte Contemporáneo, (2017), pp. 497 - 498.

Barba Robles, J.: Daniel Várquez Díazy Eva Aggerbolm en las colecciones del Reina Sofía, (cat. exp.). Sevilla: Diputación de Huelva/Centro de Arte Moderno y Contemporáneo "Manuel Vázquez Díaz". (2000).

Barchino, M. (ed.): Chile y la guerra civil española. La voz. de los intelectuales. Madrid: Calambur. (2013).

Barrionuevo, R.: Reexistencias. Escultoras del siglo XX. Madrid: Comunidad de Madrid. (2006a).

Barrionuevo, R.: "Escultoras. Obstáculos y nuevas estrategias de intervención en el espacio público". En: Arriaga Flórez, Mercedes (et. al.): Mujer, espacio y poder. Madrid: Arcibel, (2006b), pp. 46-56.

Bosch, $\mathrm{M}^{\mathrm{a}}$ del C./Montaner, P.: Pilar Montaner. Memorias. Palma de Mallorca: Ajuntament/Arxiu Municipal. (2010).

Brihuega, J.: Las vanguardias artísticas en España 1909-1936. Madrid: Itsmo. (1981).

Cabañas, M. (coord.): El arte español del siglo XX. Su perspectiva al final del milenio. Madrid: CSIC. (2001).

Camón Aznar, J.: "El crítico de arte José Francés". En: Boletín de la Real Academia de Bellas Artes de San Fernando, núm. 19, Madrid, (1964), pp. 24-26.

Cansinos Assens, R.: La novela de un literato I (1882-1914). Madrid: Alianza. (1981).

Cortés Aliaga, G.: Modernas. Historias de mujeres en el arte chileno (1900-1950). Santiago de Chile: Origo Ediciones. (2013).

Crespo, Á.: Juan Ramón Jiménezy la pintura. Salamanca: Ediciones de la Universidad. (1999).

Diego, E. de: La mujer y la pintura en el siglo XIX español. Cuatrocientas olvidadas y algunas más. Madrid: Cátedra. (1987).

García, I.: Origenes de las vanguardias artísticas en Madrid (1909-1922). Tesis doctoral. Madrid: Universidad Complutense. (2002).

García Maldonado, B.: "La mujer artista ante la crítica de arte (1910-1936)". En: $A A C A$ Digital. Revista de la Asociación Aragonesa de Críticos de Arte, núm. 17. (2011). En: https://dialnet.unirioja.es/servlet/articulo?codigo=3848561 [6-5-2017].

Gaya Nuño, J.A.: Historia de la crítica de arte en España. Madrid: Ibérico Europea de Ediciones. (1975).

Gómez de la Serna, R.: Pombo. Madrid: Trieste. (1986).

Greer, G.: La carrera de obstáculos. Vida y obra de las pintoras antes de 1950. Madrid: Bercimuel, (Traducción M. Siguero, Original en inglés 1975). (2005).

Lomba, C.: "Las artistas: entre la república y el exilio". En: Me veo, luego existo: mujeres que representan, mujeres representadas. Madrid: Consejo Superior de Investigaciones Científicas, (2015), pp. 599-516.

Lomba, C.: "El umbral hacia la libertad. Artistas en España entre 1900 y 1926". En: Illán, Margarita/Lomba, Concha (com.): Pintoras en España 1859-1926. De María Luisa de la Riva a Maruja Mallo, (cat. exp.). Zaragoza: Universidad de Zaragoza-Diputación de Zaragoza, (2016), pp. 50-69.

Mangini, S.: Las modernas de Madrid. Las grandes intelectuales de la vanguardia española. Barcelona: Península. (2001).

Mangini, S.: "El Lyceum Club de Madrid un refugio feminista en una capital hostil". En: Asparkia. Investigació feminista, núm. 17, (2006), pp. 125-140.

Mayordomo, C.: "María Luisa Pérez Herrero. Recuperando su nombre". En: Generando Arte. La Revista, núm. 0, (2014), p. 40. En: https://view.joomag.com/generando-arte-la-revista$\underline{\mathrm{n} \% \mathrm{C} 2 \% \mathrm{BA}-0 / 0705205001409771805 \text { ?page }=40}[30-8-2017]$.

Muñoz, P.: "Mujeres españolas en las artes plásticas". En: Arte, Individuo y Sociedad, núm. 21, (2009), pp. 73-88. 
Muñoz, P.: "Las mujeres como creadoras en las artes plásticas según los textos de hombres y mujeres en la España de la primera mitad del siglo XX". En: Arenal, núm. 2, Granada, (2012), pp. 393-413.

Peñarrubia Marquès, I.: Pilar Montaner i Maturana. Palma (1876-1961). Palma de Mallorca: Ajuntament de Palma. (2006).

Pereira Bueno, F.: Mulleres pintoras na arte galega (segunda metade do século XIX e primeiro terzo do século XX). Unha historia de invisibilidade. Santiago de Compostela; Consello da Cultura Galega-Comisión de Igualdade. (2009).

Pérez Segura, J.: Arte moderno, vanguardia y estado: La Sociedad de Artistas Ibéricos y la República (1931-1936): Madrid: CSIC/MEIAC. (2003).

Rodrigo Villena, I.: "Crítica de arte y polémicas de género en la España del primer tercio del siglo XX". En: Actas del XVII Congrés Nacional d'Història de l'Art. CEHA. Granada: Atrio, (2017a), pp. 1242-1256.

Rodrigo Villena, I.: "La galantería: una forma de sexismo en la crítica del arte femenino en España (1900-1936). En: Asparkia, núm. 31, (2017b), pp. 147-166.

Rodrigo Villena, I.: "Escultoras en un mundo de hombres y su fortuna en la crítica de arte española (1900-1936)”. En: Arenal, vol. 25, núm. 1, (2018), pp. 145-168.

Roussard, A. : Dictionnaire des peintres à Montmartre, XIXe \& XXe siècles. París: Editions André Roussard. (1999).

Ruiz del Árbol, M.: "Los maestros clásicos y las expresiones populares". En: Sonia Delaunay. Arte, diseño y moda (cat. exp.)". Madrid: Museo Thyssen-Bornemisza, (2017), pp. 59-69.

Ruiz del Árbol, M.:. "El arte total y Casa Sonia". En: Sonia Delaunay. Arte, diseño y moda (cat. exp.). Madrid: Museo Thyssen-Bornemisza, (2017), pp. 87-107.

Sánchez Vigil, J. M.: La Esfera: ilustración mundial (1914-1931). Madrid: Libris. (2003).

Valdebenito Carrasco, Y.: "Laura Rodig Pizarro: un caso de estudio en la historiografía del arte chileno desde un enfoque de género". En: Anales de la Historia del Arte, núm. 28, (2018), pp.225-245.

Villa, R. de la: "Crítica de arte desde la perspectiva de género". En: Investigaciones feministas, vol. 4, (2013), pp. 10-23.

Villalva Salvador, Ma P.: "José Francés, crítico de arte". Tesis Doctoral. Madrid: Universidad Complutense. (1994)

Villalva Salvador, $\mathrm{M}^{\mathrm{a}}$ P.: "El académico José Francés. Actas, documentos y escritos para la reconstrucción de una historia". En: Academia: Boletín de la Real Academia de Bellas Artes de San Fernando, núm. 90, Madrid, (2000), pp.159-191.

Villalva Salvador, Ma P.: "El crítico de arte José Francés. Una aproximación a su vida y su obra". En: Goya: Revista de Arte, núm. 285, Madrid, (2001), pp. 368-378.

Villarde Solar, D.: "María Corredoyra. Pintora membro do Seminario de Estudos Galegos e da Academia de Belas Artes da Coruña". (2009). En: Álbum de Mulleres. Conseyo da Cultura Galega. En: http://www.culturagalega.org/album/detalle.php?id=190. [27-8-2017].

\section{Hemerografía}

Anónimo: “Arte y Artistas. Victoria de Malinovska". En: $A B C$, núm. 6072, Madrid, (22 de junio de 1922), p. 20.

Anónimo: "Una pintora polaca. Victoria de Malinowska". En: Voluntad, núm. 6, Madrid, (1 de febrero de 1920), p. 9.

Francés, J.: "De Norte a Sur. Las labores impropias del sexo". En: La Esfera, núm. 81, Madrid, (17 de julio de 1915a), p. 29.

Francés, J.: "De Norte a Sur. Vigilantes femeninos". En: La Esfera, núm. 81, Madrid, (17 de julio de 1915b), p. 29.

Francés, J.: "De norte a sur. Elena Dutrieu". En: La Esfera, núm. 83, Madrid, (31 de julio de 1915), p. 19. 
Francés, J.: "El arte catalán contemporáneo. Irene Narezo". En: La Esfera, núm. 91, Madrid, (25 de septiembre de 1915), pp. 8-9.

Francés, J.: "De norte a sur. Las amazonas del odio. Miss Gertrudis Whitney”. En: La Esfera, núm. 138, Madrid, (19 de agosto de 1916), p. 29.

Francés, J.: "Los pintores íntegros". En: El Año artístico 1915. Madrid: Mundo Latino, (1916a), pp. 52-53.

Francés, J.: "Los dos artistas decoradores. Los hermanos Gutiérrez Larraya". En: El Año Artístico 1915. Madrid: Mundo Latino, (1916b), pp. 55-56.

Francés, J.: "Sobre el arte en Cataluña". En: El Año Artístico 1915. Madrid: Mundo Latino, (1916c), pp. 213-214.

Francés, J.: "Irene Narezo". En: El Año Artístico 1915. Madrid: Mundo Latino, (1916d), pp. 236-238.

Francés, J.: "De norte a sur. Las damas blancas". En: La Esfera, núm. 198, Madrid, (13 de octubre de 1917), p. 21.

Francés, J.: "Exposiciones catalanas". En: El Año Artístico 1916. Madrid: Mundo Latino, (1917a), pp. 18-19.

Francés, J.: "La exposición de Valencia". En El Año Artístico 1916. Madrid: Mundo Latino, (1917b), pp. 250-254.

Francés, J.: "Una pintora checa: Milada Sindlerova". En: El Año Artístico 1917. Madrid: Mundo Latino, (1918a), pp. 37-40.

Francés, J.: "Un banquete". En: El Año Artístico 1917. Madrid: Mundo Latino, (1918b), pp. 210-215.

Francés, J.: "Memoranda". En: El Año Artístico 1917. Madrid: Mundo Latino, (1918c), pp. 216-217.

Francés, J.: "La Exposición de Arte Gallego en La Coruña". En: El Año Artístico 1917. Madrid: Mundo Latino, (1918c), pp. 341-369.

Francés, J.: "La escultora Marta Spitzer". En: El Año Artístico 1917. Madrid: Mundo Latino, (1918d), pp. 387-389.

Francés, J.: "Dos artistas decoradores: los hermanos Gutiérrez Larraya”. En: El Año Artístico 1918. Madrid: Mundo Latino, (1919a), pp. 97-98.

Francés, J.: "Una exposición de pintores polacos". En: El Año Artístico 1918. Madrid: Mundo Latino, (1919b), pp. 119-122.

Francés, J.: "La exposición de pintura francesa". En: El Año Artístico 1918. Madrid: Mundo Latino, (1919c), pp. 155-166.

Francés, J.: "La Exposición de Pintura Francesa. Algunos Pintores Franceses. Rosa Bonheur". En: El Año Artístico 1918. Madrid: Mundo Latino, (1919d), pp. 166-170.

Francés, J.: "La pintora mallorquina Pilar Montaner". En El Año Artístico 1918. Madrid: Mundo Latino, (1919e), pp. 344-347.

Francés, J.: "Celso Lagar y sus planismos". En: El Año Artístico 1918. Madrid: Mundo Latino, (1919f), pp. 353-354.

Francés, J.: "Otras exposiciones”. En: El Año Artístico 1918. Madrid: Mundo Latino, (1919g), p. 356.

Francés, J.: "Exposiciones en Madrid. II. Barradas el vibracionista". En: El Año Artístico 1919. Madrid: Mundo Latino, (1920a), pp. 118-119.

Francés, J.: “Artes de la mujer. El encaje”. En: El Año Artístico 1919. Madrid: Mundo Latino, (1920b), pp. 222 y 229.

Francés, J.: "La exposición de Santander. VII. Apostillas en el catálogo". En: El Año Artístico 1919. Madrid: Mundo Latino, (1920c), p. 311.

Francés, J.: "El VI Salón de humoristas y la crítica". En: El Año Artístico 1920. Madrid: Mundo Latino, (1921a), pp. 43-47.

Francés, J.: "Otras exposiciones. Victoria de Malinowska". En: El Año Artístico 1920. Madrid: Mundo Latino, (1921b), pp. 158-159.

Francés, J.: “Aurora Gutiérrez Larraya”. En: El Año Artístico 1920. Madrid: Mundo Latino, (1921c), p. 183. 
Francés, J.: "La exposición Nacional de Bellas Artes". En: El Año Artístico 1920, Madrid: Mundo Latino, (1921d), pp. 247-248.

Francés, J.: "La Exposición Nacional de Bellas Artes. VIII. El Arte decorativo". En: El Año Artístico 1920. Madrid: Mundo Latino, (1921e), pp. 252-256.

Francés, J.: "El arte de Sonia". En: El Año Artístico 1920. Madrid: Mundo Latino, (1921f), pp. 392-394.

Francés, J.: “La exposición Vázquez Díaz: II.- Una escultora danesa: Eva Aggerholm”. En: El Año Artístico 1921. Madrid: Mundo Latino, (1922), pp. 77-79.

Francés, J.: “Georgina Agutte o la fidelidad conyugal". En: El Año Artístico 1922, Madrid: Mundo Latino, (1923a), p. 186-188.

Francés, J.: "Cuatro pintores modernos". En: El Año Artístico 1922. Madrid: Mundo Latino, (1923b), p. 248.

Francés, J.: "Una pintora paisajista". En: El Año Artístico 1923. Madrid: Mundo Latino, (1924a), pp. 46-49.

Francés, J.: "Los acuarelistas portugueses". En: El Año Artístico 1923. Madrid: Mundo Latino, (1924b), pp. 162-167.

Francés, J.: "Dos artistas hispanoamericanos: José Antonio Terry y Laura Rodig”. En: El Año Artístico 1924. Madrid: Mundo Latino, (1925), pp. 417-420.

Francés, J.: “Las exposiciones del 'Lyceum'. Una pintora argentina”. En: La Esfera, núm. 704, Madrid, (2 de julio de 1927), p. 21.

Francés, J.: "Una pintora gallega: María Corredoira". En: El Año Artístico 1925. Barcelona: Editorial Lux, (1928a), pp. 166-167.

Francés, J.: "Paisajes de Flandes por una española". En: El Año Artístico 1925. Barcelona: Editorial Lux, (1928b), pp. 206-207.

Francés, J.: "María y Elena Sorolla o la fraterna sonrisa melancólica". En: El Año Artístico 1926. Barcelona: Editorial Lux, (1928c), pp. 422-425.

García Maroto, G.: El año artístico (Relación de sucesos acaecidos en el arte español el año de 1912). Madrid: Imprenta de José Fernández Díaz. (1913).

Melida, J. R.: "Informe acerca de la obra titulada El Año Artístico de que es autor José Francés". En: Boletín de la Real Academia de Bellas Artes de San Fernando, Madrid, (1924), pp. 68-69.

Romeu, J. (pseudónimo de Carme Karr): "La pintora mallorquina Pilar Montaner de Sureda". En: Feminal, núm. 122, Barcelona, (24 de junio de 1917), pp. 2-5. 